\title{
Novel Class of Psychedelic Iboga Alkaloids Disrupts Opioid Addiction States
}

Václav Havel ${ }^{1 \#}$, Andrew C. Kruegel ${ }^{1 \#}$, Benjamin Bechand ${ }^{1 \#}$, Scot Mclntosh ${ }^{2}$, Leia Stallings ${ }^{2}$, Alana Hodges $^{2}$, Madalee G. Wulf ${ }^{1}$, Melissa Nelson ${ }^{3,4}$, Amanda Hunkele $^{5,6}$, Mike Ansonoff7, John E. Pintar $^{7}$, Christopher Hwu ${ }^{1}$, Najah Abi-Gerges ${ }^{8}$, Saheem A. Zaidi ${ }^{9,10}$, Vsevolod Katritch ${ }^{9,10}$, Mu Yang $^{11,12}$, Jonathan A. Javitch ${ }^{3,4}$, Susruta Majumdar ${ }^{5}$, Scott E. Hemby ${ }^{2}$ and Dalibor Sames ${ }^{1,13} \square$

${ }^{1}$ Department of Chemistry, Columbia University, New York, NY, USA. ${ }^{2}$ Department of Basic Pharmaceutical Sciences, Fred Wilson School of Pharmacy, High Point University, High Point, NC, USA. ${ }^{3}$ Department of Psychiatry, and Department of Molecular Pharmacology and Therapeutics, Columbia University, New York, NY, USA. ${ }^{4}$ Division of Molecular Therapeutics, New York State Psychiatric Institute, New York, NY, USA. ${ }^{5}$ Center for Clinical Pharmacology, University of Health Sciences \& Pharmacy at St Louis and Washington University School of Medicine, St Louis, MO 63110, USA. ${ }^{6}$ Department of Neurology and Molecular Pharmacology, Memorial Sloan Kettering Cancer Center, New York, NY 10021, USA. ${ }^{7}$ Department of Neuroscience and Cell Biology, Rutgers University, New Jersey, NJ 08854, USA. ${ }^{8}$ AnaBios Corporation, 3030 Bunker Hill St., Suite 312, San Diego, CA 92109, USA. ${ }^{9}$ Department of Quantitative and Computational Biology, University of Southern California, Los Angeles, CA 90089, USA. ${ }^{10}$ Department of Chemistry, Bridge Institute, Michelson Center for Convergent Sciences, University of Southern California, Los Angeles, CA 90089, USA. ${ }^{11}$ Institute for Genomic Medicine, Columbia University Irving Medical Center, New York, NY, 10032, USA. ${ }^{12}$ Mouse Neurobehavioral Core facility, Columbia University Irving Medical Center, New York, NY, 10032, USA. ${ }^{13}$ The Zuckerman Mind Brain Behavior Institute at Columbia University, New York, NY, USA. \#These authors contributed equally. $\square$ email: ds584@columbia.edu

\section{Abstract}

Substance use and related mental health epidemics are causing increasing suffering and death in diverse communities. ${ }^{1,2}$ Despite extensive efforts focused on developing pharmacotherapies for treating substance use disorders, currently approved medications do not reverse the persistent neurocircuitry and psychological changes that underlie addiction states, highlighting an urgent need for radically different therapeutic approaches. ${ }^{3,4}$ Ibogaine provides an important drug prototype in this direction, as a psychoactive iboga alkaloid suggested to have the ability to interrupt maladaptive habits including opioid use in drug-dependent humans. ${ }^{5}$ However, ibogaine and its major metabolite noribogaine present considerable safety risk associated with cardiac arrhythmias. ${ }^{6}$ We introduce a new class of iboga alkaloids - "oxa-iboga" - defined as benzofurancontaining iboga analogs and created via structural editing of the iboga skeleton. The oxa-iboga compounds act as potent kappa opioid receptor agonists in vitro and in vivo but exhibit atypical behavioral features compared to standard kappa psychedelics. We show that oxa-noribogaine has greater therapeutic efficacy in addiction models and no cardiac pro-arrhythmic potential, compared to noribogaine. Oxa-noribogaine induces long-lasting suppression of morphine intake after a single dose in rat models of addiction and persistent reduction of morphine intake after a short treatment regimen. Oxa-noribogaine maintains and enhances the ability of iboga compounds to effect lasting alteration of addiction-like states while addressing iboga's cardiac liability. As such, 
oxa-iboga compounds represent candidates for a new kind of anti-addiction pharmacotherapeutics.

Ibogaine is the major psychoactive alkaloid found in the iboga plant (Tabernanthe iboga), a shrub native to West Central Africa. ${ }^{5}$ While the root bark has been harvested as a ceremonial and healing commodity in Africa for centuries, the use of iboga plant or pure ibogaine has recently become a world-wide movement with growing numbers of ibogaine healers, providers and clinics, largely driven by the growing crises of drug addiction, trauma, despair, and spiritual starvation. ${ }^{2,7,8}$ Ibogaine induces profound psychedelic effects that typically include dream-like states (oneiric effects), panoramic and interactive memory recall, experiences of death and rebirth, confrontation with personal trauma, and loosening of maladaptive habits. ${ }^{9}$ Ibogaine is unique among other psychedelics for its ability to rapidly interrupt opioid drug dependence. ${ }^{10}$ Although rigorous demonstration of clinical efficacy via controlled clinical trials is pending, the profound anti-addiction effects of ibogaine have been amply documented in anecdotal reports and open label clinical trials, including rapid and long-lasting relief of drug cravings, increased duration of abstinence, as well as long term reduction of anxious and depressive symptoms. ${ }^{11-13}$ The clinical claims of ibogaine's anti-addictive properties have been recapitulated in numerous rodent models of substance use disorders (SUDs) and depression. ${ }^{14-17}$

Ibogaine has a complex chemical structure where the tryptamine motif is intricately embedded in the isoquinuclidine ring, leading to a polycyclic tryptamine system that defines the iboga alkaloids (Fig. 1a, d). ${ }^{18}$ The pharmacology of ibogaine is equally complex, featuring a polypharmacological profile, comprising ibogaine and its main metabolite noribogaine - a dominant circulating species. The known molecular targets for both ibogaine and noribogaine include $\mathrm{N}$-methyl-D-aspartate receptor (NMDAR, channel blocker), $\alpha 3 \beta 4$ nicotinic receptor (antagonist), serotonin transporter (SERT, inhibitor), and kappa opioid receptor (KOR, agonist). ${ }^{19}$ Mechanistically, ibogaine thus appears to bridge several different classes of psychoactive substances, including the "anesthetic psychedelics" (NMDAR blockers such as phencyclidine (PCP) or ketamine), "kappa psychedelics" (KOR agonists such as salvinorin A or U50,488), and monoamine reuptake inhibitors (such as imipramine), but shows no direct interaction with the 5-hydroxytryptamine 2 receptors (5HT2R), setting ibogaine apart from the classical psychedelics (Fig. 1a, b). We have developed new synthetic methods for de novo synthesis of the iboga alkaloid scaffold, which unlocks unlimited exploration of its structure and pharmacology (Fig. 1c). ${ }^{20,21}$ Specifically, we developed and optimized a nickel-catalyzed process that enables preparation of the benzofuran iboga analogs (Extended Data Fig. 1). These novel analogs show greatly potentiated KOR activity on the iboga pharmacological background, constituting a new class of iboga alkaloids (Fig. 1). 

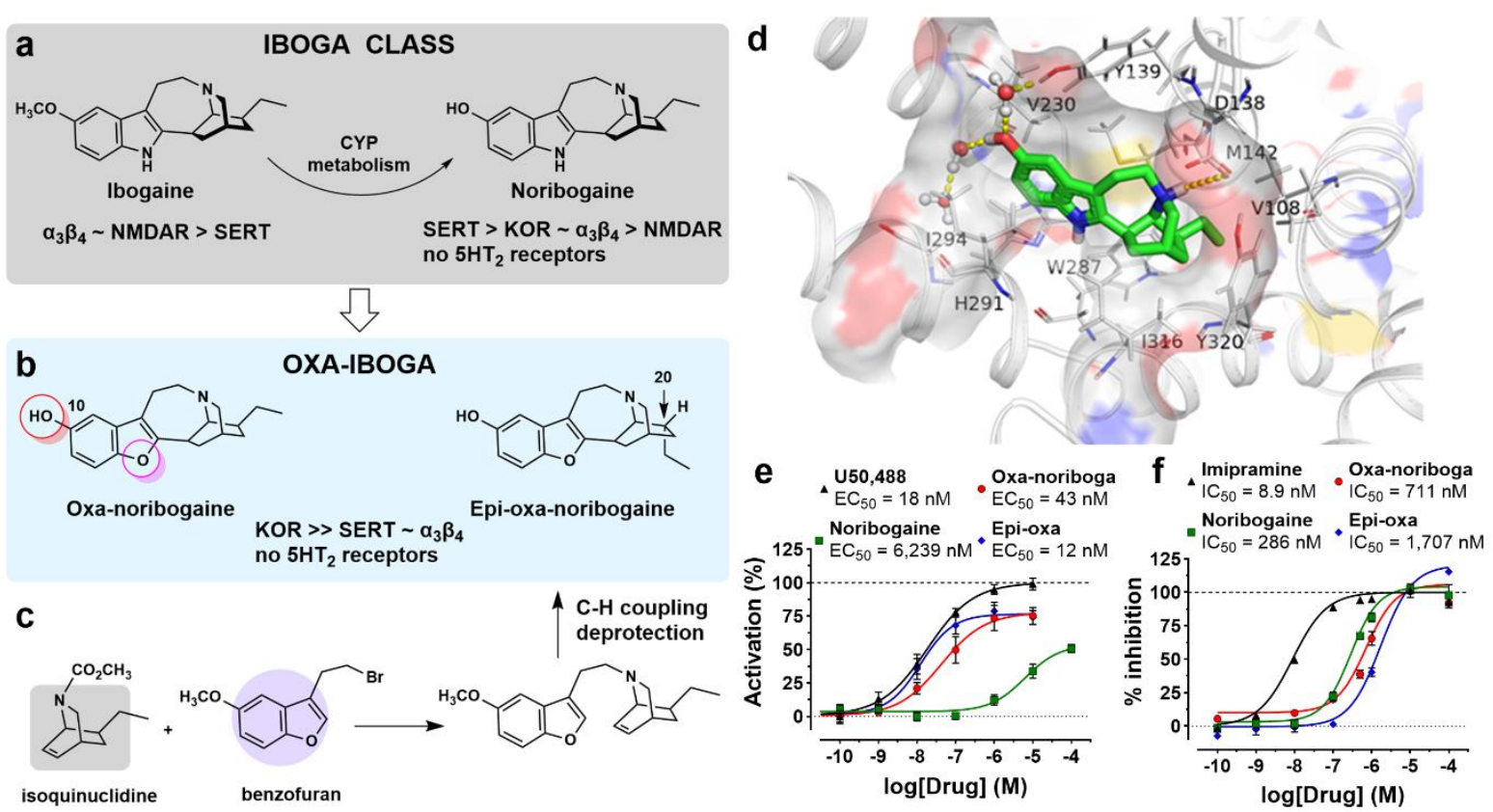

Fig. 1 | Oxa-iboga is a novel class of iboga alkaloids discovered by structural editing of ibogaine enabled by efficient de novo chemical synthesis. a, Ibogaine is a unique probe drug with profound clinical effects and complex pharmacology that is distinct from classical psychedelic tryptamines. Relative potencies at known molecular targets are shown. b, Oxa-iboga analogs are defined by the replacement of indole with benzofuran, resulting in accentuation of the KOR activity on the iboga pharmacological background. c, De novo synthesis of iboga molecular framework rests on the catalytic union of the two main structural components of oxa-iboga skeleton, the isoquinuclidine and benzofuran ring systems. $\mathbf{d}$, Docking pose of noribogaine (green) in sticks representation inside KOR structure (active receptor state). Hydrogen bonding near the C10 phenol is highlighted by yellow dashed lines. e, Oxa-noribogaine analogs are high efficacy agonists of rat KOR in vitro as demonstrated by $G$ protein BRET assay. $f$, Inhibition of human serotonin transporter (hSERT) by noribogaine and oxa-iboga analogs. KOR (kappa opioid receptor), $\alpha 3 \beta 4$ ( $\alpha 3 \beta 4$ nicotinic acetylcholine receptors), SERT (serotonin transporter), 5HT (serotonin), NMDAR ( $N$-methyl-D-aspartate receptor). Data are presented as mean \pm SEM.

\section{Oxa-iboga analogs are potent KOR agonists in vitro}

Noribogaine, the starting and comparison point for our studies, acts as a KOR partial agonist in a bioluminescence resonance energy transfer (BRET) assay for $\mathrm{G}$ protein activation (rat $\mathrm{KOR}, \mathrm{EC}_{50}=$ $6.2 \mu \mathrm{M}, \mathrm{E}_{\max }=54 \%$, Fig. 1e, Table S3), consistent with previous reports. ${ }^{22}$ We found that substitution of the indole $\mathrm{NH}$ group in noribogaine with oxygen dramatically accentuates KOR activity: oxanoribogaine binds to the KOR (mKOR, $\left.\mathrm{K}_{\mathrm{i}}=41 \mathrm{nM}\right)$, activates $\mathrm{G}$ protein in the $\left.{ }^{35} \mathrm{~S}\right] \mathrm{GTP} Y \mathrm{~S}$ assay $\left(\mathrm{mKOR}, \mathrm{EC}_{50}=49 \mathrm{nM}, \mathrm{E}_{\max }=92 \%\right)$ and $\mathrm{BRET}$ assay $\left(\mathrm{rKOR}, \mathrm{EC}_{50}=43 \mathrm{nM}, \mathrm{E}_{\max }=78 \%\right.$ ), resulting in a large left shift in potency versus noribogaine (Fig. 1e, Table S3). Oxa-noribogaine is more than tenfold selective for KOR versus MOR and about seven-fold over DOR in the ${ }^{35}$ S] GTP $Y S$ binding assay using mouse opioid receptors (Extended Fig. 2). The phenol group in the 10-position is the essential component of both the iboga and oxa-iboga KOR pharmacophores, as agonist activity is lost if the phenol is masked or removed (Table S5). Noribogaine's binding pose obtained by docking to the 
active KOR state identified water mediated hydrogen-bonding interactions between the C10 phenolic hydroxyl and tyrosine $139^{3.33}$ residue, as well as an ionic interaction between the isoquinuclidine amine and acidic aspartate $138^{3.32}$ residue (Fig. 1d). The KOR potency and selectivity can be further modulated by the inversion of the geometry of the C20 center, such as in the endo-epimer, epi-oxa-noribogaine (epi-oxa), although the effects are relatively modest (Fig. $1 e)$.

For the rest of iboga pharmacology, SERT is arguably the most rigorously validated molecular target of noribogaine. ${ }^{23,24}$ The oxa-iboga compounds largely maintain 5HT reuptake inhibitory activity with a modest loss of potency as compared to noribogaine $\left(\mathrm{IC}_{50}\right.$ (oxa-noriboga) $=711 \mathrm{nM}$ versus $I C_{50 \text { (noriboga) }}=286 \mathrm{nM}$, Fig. 1f). Similarly, the inhibitory activity of oxa-noribogaine at the $\alpha 3 \beta 4$ nicotinic receptors is comparable to that of noribogaine with a marginal increase in potency $\left(\mathrm{IC}_{50}=\right.$ $2.9 \mu \mathrm{M}$ vs $\mathrm{IC}_{50}=5.0 \mu \mathrm{M}$, Extended Fig. 2). A broad receptor screen showed a favorable pharmacological profile (Table S9) with more than 100-fold separation in binding potency between KOR and non-opioid human targets (with the exception of SERT and $\alpha 3 \beta 4$ molecular targets).

\section{Oxa-noribogaine shows potent analgesia, no aversion, and separation of analgesic and psychedelic-like effects}

Oxa-noribogaine induces potent antinociceptive effects in mice in the tail-flick assay (thermal nociception) with comparable potency to the standard KOR agonist, U50,488 (Fig. 2a, ED 50 (oxanoriboga) $=3.0 \mathrm{mg} / \mathrm{kg}$ vs $E_{50}\left(\mathrm{U}_{50}\right)=2.2 \mathrm{mg} / \mathrm{kg}$; s.c. administration). In KOR knock-out (KOR-KO) mice, the analgesic effect is lost up to a $10 \mathrm{mg} / \mathrm{kg}$ dose, a result of a one-log-unit right shift in the dose response curve $\left(E D_{50(W T)}=3.0 \mathrm{mg} / \mathrm{kg}\right.$ to $E D_{50(K O R-K O)}=20.6 \mathrm{mg} / \mathrm{kg}$, Fig. $\left.2 \mathrm{~b}\right)$. Using MOR knock-out (MOR-KO) mice, there was a small right shift in dose curve, (Fig. 2b, ED 50 (MOR-KO) $=7.0 \mathrm{mg} / \mathrm{kg}$ ). Epioxa-noribogaine also induces a potent antinociceptive effect which is abolished in KOR-KO mice, while a marginal right shift was observed in MOR-KO mice (Fig. $2 \mathrm{C}, \mathrm{ED}_{50(\mathrm{WT})}=1.3 \mathrm{mg} / \mathrm{kg}, \mathrm{ED}_{50 \text { (KOR- }}$ $\mathrm{KO})=\mathrm{n} . \mathrm{d}$., $\left.\mathrm{ED}_{50(\mathrm{MOR}-\mathrm{KO})}=2.0 \mathrm{mg} / \mathrm{kg}\right)$. These results indicate that KOR drives the antinociceptive activity of these compounds with only a minor contribution from MOR in the case of oxanoribogaine. Pharmacological studies with opioid receptor antagonists support this interpretation and show that the delta opioid receptors (DOR) do not contribute to the analgesic effect (Extended data Fig. 4). The analgesia test not only indicates a desirable therapeutic-like effect, but also provides a useful physiological readout for functional KOR engagement in vivo, that enables dosing calibration for behavioral studies (vide infra).

It is well established that KOR agonists induce dose-dependent hallucinosis in humans, accompanied by sedation and mood worsening in healthy subjects. ${ }^{25}$ In rodents and other species, kappa psychedelics also induce a sedation-like phenotype characterized by reduced locomotor activity without a complete loss of ambulatory functions (animals respond to gentle physical stimulation). Although sedation is a non-specific behavioral effect, in the context of kappa psychedelics, it is KOR dependent and thus can serve as a simple preclinical proxy for assessing KOR agonism in mice, which is typically associated with psychedelic effects. At nearly maximal analgesic doses (e.g. $E D_{80}, 5.4 \mathrm{mg} / \mathrm{kg}$ ), oxa-noribogaine did not induce sedation in mice, indicated by locomotor activity comparable to that of the vehicle group in the open field (OF) test (Fig. 2d, e). In stark contrast, epi-oxa-noribogaine induced a strong sedative effect at an equianalgesic dose, and this effect was completely reversed by KOR antagonist aticaprant (Fig. 2f). Thus, these two stereoisomers, while producing analgesia with similar potency, show major 
differences in psychedelic-like effects in mice. However, at supra-analgesic doses of oxanoribogaine (> $10 \mathrm{mg} / \mathrm{kg}$, s.c.), sedation in mice is observed (Extended data Fig. 4b). Thus oxanoribogaine provides a differential dosing window between the analgesia and psychedelic-like effects, in contrast to epi-oxa and typical kappa psychedelics where the sedation dosedependence approximately follows the analgesic one (Extended data Fig. 4c).

We next examined oxa-noribogaine in the conditioned place preference/aversion (CPP/CPA) paradigm used to assess rewarding or aversive effects of drugs. Typical kappa psychedelics show aversive effects, or CPA, while drugs of abuse produce CPP in this test. ${ }^{26}$ Oxa-noribogaine showed no CPA or CPP at supra-analgesic doses, indicating no aversion or abuse liability (Fig. $2 \mathrm{~g}$ ). Typical kappa psychedelics also induce worsening of mood in healthy humans and pro-depressive-like effects in rodents in the forced swim test. ${ }^{25,27}$ Oxa-noribogaine demonstrated no acute depressive-like effects in mice at highly analgesic doses (Fig. 2h). This indicates that even at high functional engagement of KOR, pro-depressive or aversive behavioral effects are not induced by this compound.

A pharmacokinetic profile of systemically administered oxa-noribogaine was investigated in mice (Fig. 2i) and rats (Extended Data Fig. 3). Oxa-noribogaine is highly brain penetrant and the estimated free drug concentrations in the brain after analgesic doses match well with the in vivo physiological readouts and in vitro pharmacological parameters (Extended Data Fig. 3 and Supplementary Information).

In summary of the in vitro and in vivo pharmacology, oxa-noribogaine is an atypical KOR agonist that exerts potent analgesia in the absence of common side effects of kappa psychedelics, namely acute aversion and pro-depressive behaviors. Oxa-noribogaine also provides a pharmacological window for induction of efficacious antinociceptive effects with no or limited sedation. 


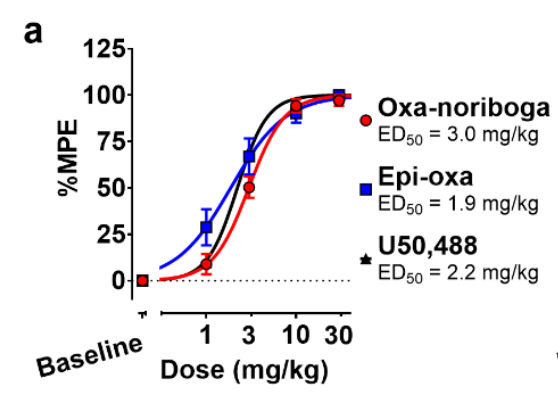

d
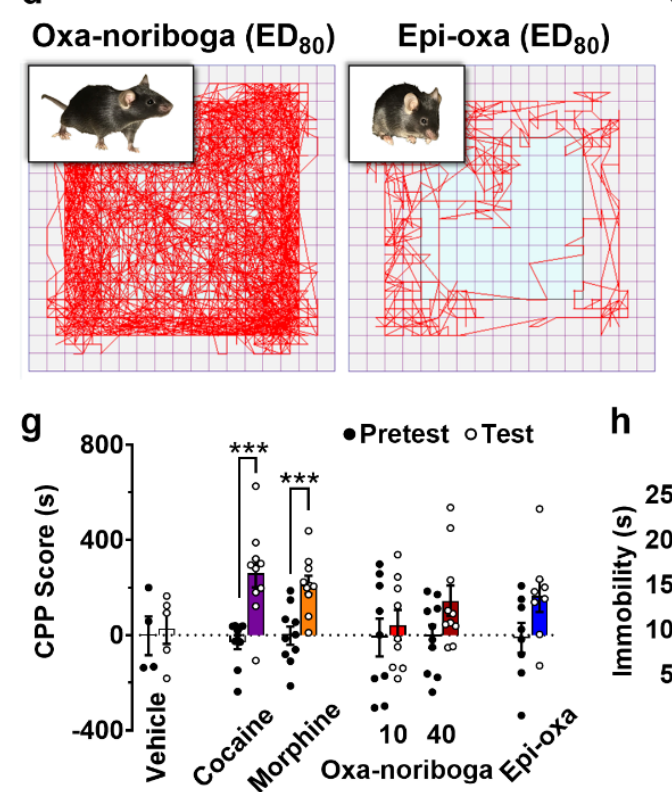

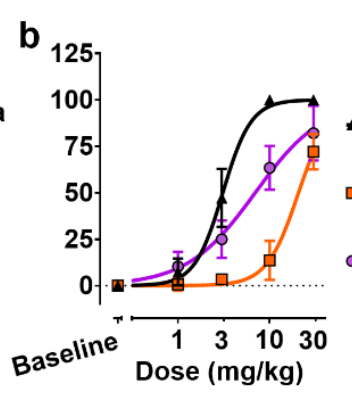

e
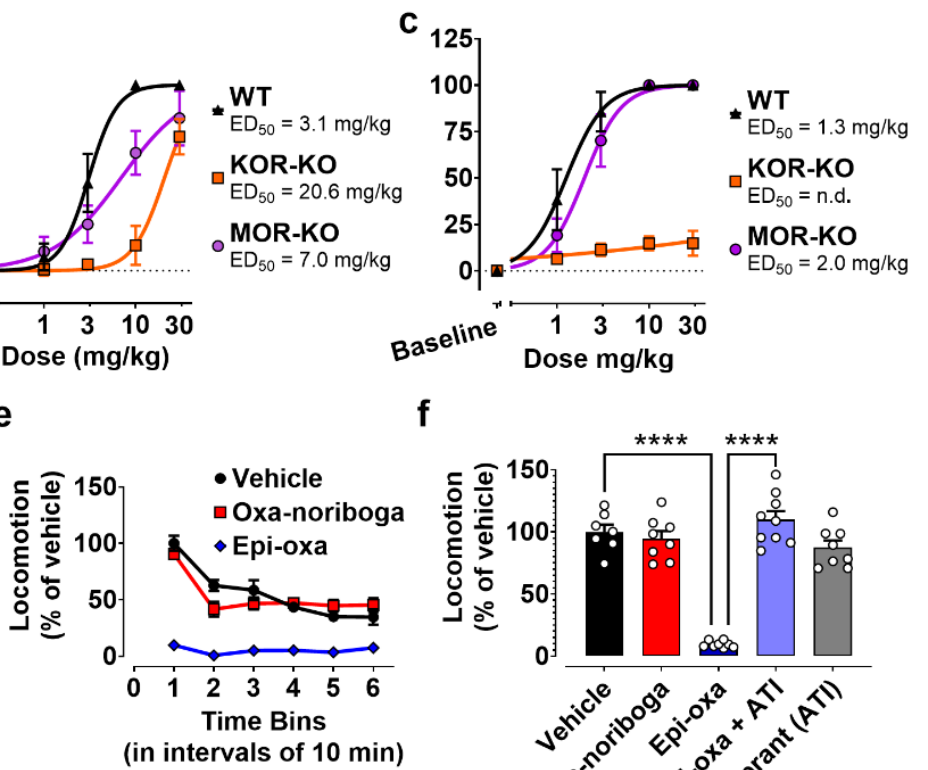

f
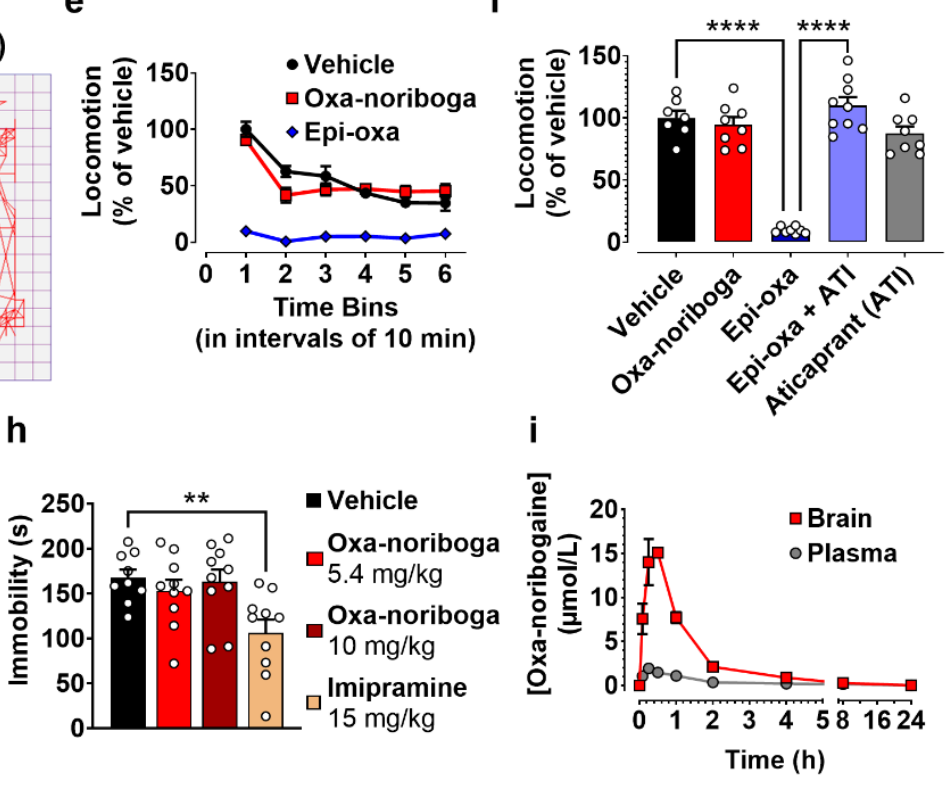

Fig. 2 Oxa-noribogaine is an atypical KOR agonist in vivo with potent analgesic effect, no aversion, and no psychedelic-like effects at efficacious analgesic doses. a, Oxa-iboga analogs induce potent analgesia in the mouse tail-flick test, comparable in potency and efficacy to the standard kappa psychedelic, U50,488. Analgesia of oxa-noribogaine $\mathbf{b}$, and epi-oxa-noribogaine $\mathbf{c}$, is KOR dependent as demonstrated in KOR knock-out mice (KOR KO), compared to mu receptor knock-out (MOR KO) and wild type (WT) mice (KOR KO vs WT, P<0.0001). d, Traces visualizing ambulatory distance traveled by WT mice in open field test (OF) after drug administration show that oxa-noribogaine causes no sedation at a high analgesic dose (analgesic $E_{80}, 5.4 \mathrm{mg} / \mathrm{kg}$ ), in contrast to epi-oxa-noribogaine ( $E D_{80}=5.2 \mathrm{mg} / \mathrm{kg}$ ) which is profoundly sedative. e, Quantification of OF test ( $E D_{80}$ doses) for oxa-noribogaine and epi-oxa-noribogaine, data are normalized to locomotion of vehicle. $f$, Sedation of epi-oxa-noribogaine $(P<0.0001)$ is KOR-driven as demonstrated by pre-treatment $(P<0.0001)$ by the selective KOR antagonist aticaprant (ATI). Sedation serves as a proxy in mice for psychedelic effects of kappa agonists in humans. Total locomotion over 60 min period normalized to vehicle. $g$, Mice do not develop conditioned place preference or aversion (CPP/CPA) after administration of oxa-noribogaine $(10 \mathrm{mg} / \mathrm{kg}$ : $\mathrm{P}=0.84767$; $40 \mathrm{mg} / \mathrm{kg}: \mathrm{P}=0.2546)$ or epi-oxa-noribogaine $(40 \mathrm{mg} / \mathrm{kg}: \mathrm{P}=0.0768)$ analogs. Significant place preferences were observed for cocaine $(10 \mathrm{mg} / \mathrm{kg}: \mathrm{P}=0.0004)$ and morphine $(20 \mathrm{mg} / \mathrm{kg}: \mathrm{P}=$ 0.0008). $\mathbf{h}$, No pro-depressive-like effects were detected using the forced swim test after oxanoribogaine administration (30 min post administration). i, Pharmacokinetic distribution of oxa- 
noribogaine in mice plasma and brain tissue reveals high brain penetration. The maximal brain concentration is reached $\sim 30$ min after injection. Data are presented as mean $\pm \mathrm{SEM}$, specific statistical tests, information on reproducibility, and $P$ values are reported in Methods and in Supplementary Statistics Table, $* P<0.05, * * P<0.01, * * * P<0.001, * * * * P<0.0001$.

Oxa-iboga compounds do not show pro-arrhythmia risks in adult primary human heart cells.

The use of ibogaine has been associated with severe cardiac side effects, most notably cardiac arrhythmias and sudden death in humans. It has been suggested that these adverse effects are linked to the inhibition of the human ether-a-go-go-related gene (hERG) potassium channels by both ibogaine and noribogaine. ${ }^{6} \mathrm{hERG}$ inhibition can result in retardation of cardiomyocyte action potential repolarization and prolongation of the QT interval in the electrocardiogram, thus increasing the risk of arrhythmias. As most of the reported adverse effects occurred $>24$ hours post ibogaine ingestion, noribogaine with its long circulation and large exposure appears to be the culprit of cardiac risks. ${ }^{6}$ This hypothesis is supported by a recent dose escalation clinical study that reported a linear relationship between the cardiac QT interval prolongation and the plasma noribogaine concentration. ${ }^{28}$

Preclinical assessment of cardiotoxicity of novel compounds is complicated by species differences in cardiac ion channel expression and pharmacology. Further, inhibition of the hERG channel alone is not sufficient to predict delayed ventricular repolarization and cardiac proarrhythmia risk, as modulation of other ion channels involved in different phases of the cardiac action potential may mitigate or exacerbate the QT prolongation/pro-arrhythmia risk. This is particularly relevant for compounds like iboga alkaloids with complex pharmacology and multiion-channel activities. ${ }^{29}$ For example, ibogaine shows no effect on repolarization in guinea pig cardiomyocytes, likely due to the compensatory effects induced by the enhanced inhibition of Ltype calcium channels in this species versus human. ${ }^{30}$ As a result, preclinical in vivo tests in rodents or other non-human species may be misleading.

We therefore used adult human primary cardiomyocytes in a state-of-the-art assay with high predictive validity of clinical cardiac effects. ${ }^{29}$ Adult human primary ventricular myocytes are isolated from ethically consented donor hearts, and field stimulated to induce stable contractility transients (Fig. 3). The assay detects pro-arrhythmic events such as after-contractions and contraction failures, and has been validated with clinically characterized drugs including proarrhythmic drugs and non-pro-arrhythmic drugs. The assay has high sensitivity and specificity, and outperforms many other assays due to the phenotypic stability of adult primary cardiomyocytes compared to human stem cell-derived cardiomyocytes. ${ }^{29,31}$

Based on available noribogaine clinical data, we expected its plasma concentrations above 300-400 nM to be associated with a considerable pro-arrhythmia risk in this assay. ${ }^{28}$ As such, we tested it in the clinically relevant concentration range $0.1-10 \mu \mathrm{M}$, for more information see Extended Data Fig. 3, 5 and the Methods section).

As expected, noribogaine shows a concentration-dependent pro-arrhythmia risk in the human cardiomyocyte assay eliciting an increasing incidence of aftercontractions and contraction failures (Fig. 3b, c). Greater than $20 \%$ incidence of any of the arrhythmia-associated events indicates a considerable pro-arrhythmia risk, which was observed at concentrations of $1 \mu \mathrm{M}$ or higher. In contrast, oxa-noribogaine or epi-oxa-noribogaine showed no pro-arrhythmic potential at any of the concentrations tested. In mice, a $10 \mathrm{mg} / \mathrm{kg}$ dose of oxa-noribogaine induces a maximal 
analgesic effect and produces a free plasma $C_{\max }$ of $\sim 130 \mathrm{nM}$ (estimated from $\mathrm{PK}$ and plasma protein binding), which represents the upper end of therapeutic free plasma concentration and indicates a large margin of safety with respect to pro-arrhythmia risk. We hypothesize that the observed differences in pro-arrhythmia risks between the oxa-iboga and iboga compounds are related to the activity at multiple ion channels of these compounds. However, to elucidate the precise mechanisms will require detailed follow-up studies, which are beyond the scope of this report.

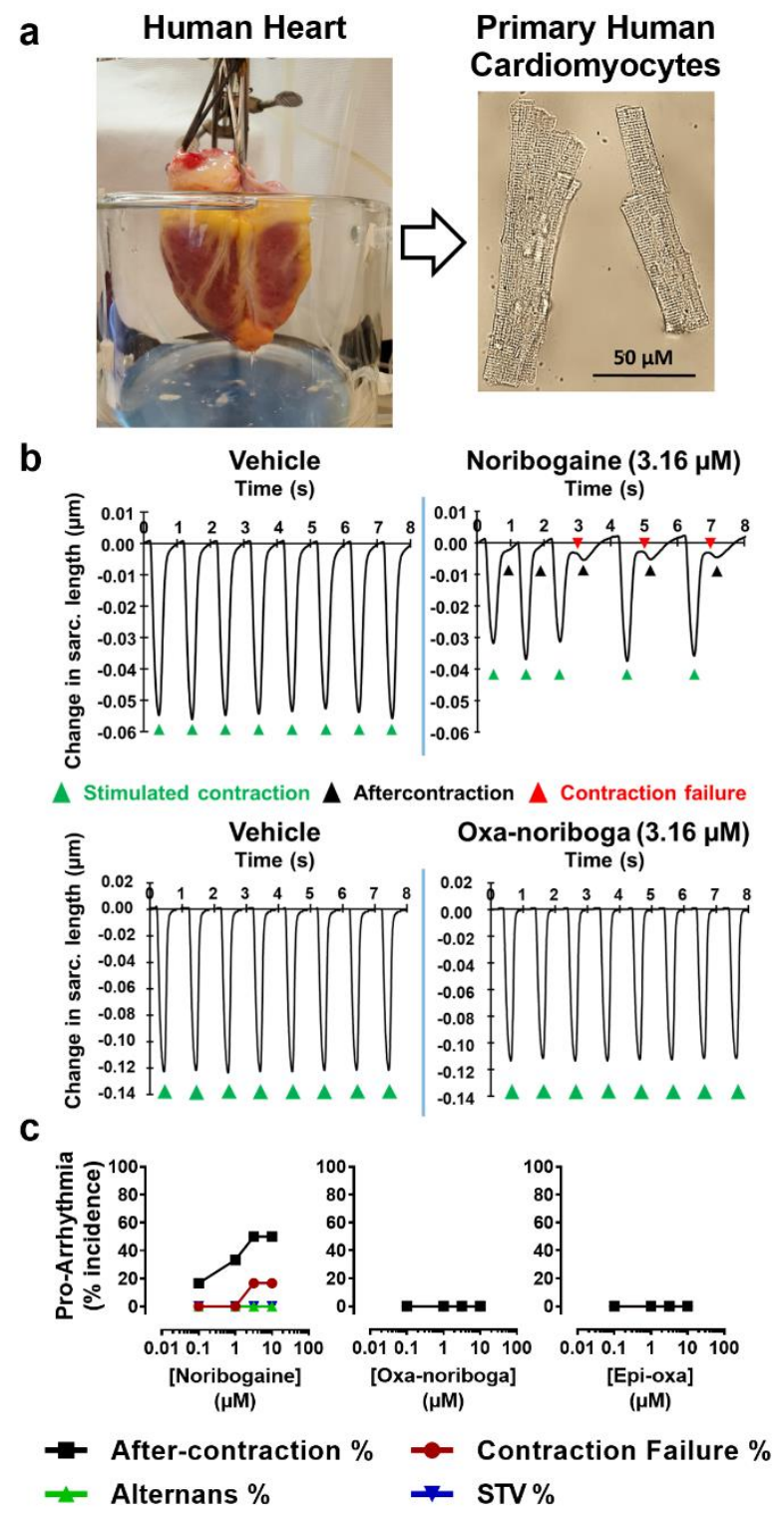


Fig. 3 | Oxa-iboga analogs do not show pro-arrhythmia risk in adult human primary cardiomyocytes. a, Human heart is digested to isolate single cardiomyocytes, which are field stimulated to produce a regular pattern of contractility transients. These cells are phenotypically stable and provide a robust preclinical assay with high translational validity. b, Representative traces capturing contraction-induced change in sarcomere length after administration of vehicle, noribogaine and oxa-noribogaine solutions. c, Noribogaine demonstrates pro-arrhythmic potential by causing after-contractions and contraction failures in cardiomyocytes as quantified in the plot, providing validation of this assay for the iboga compounds. No pro-arrhythmic potential was detected for oxa- or epi-oxa-noribogaine (See Extended Data Fig. 5 for information on replicates).

\section{Oxa-noribogaine induces acute and persistent suppression of morphine self-administration}

To assess the therapeutic potential of oxa-noribogaine we adopted a widely used model of opioid use disorder (OUD) and other SUDs, the rat intravenous self-administration (SA) paradigm. ${ }^{32}$ In this behavioral assay, animals are trained to respond on an operant to receive intravenous infusions of a drug while discrete stimuli (tone and light) are paired with the drug delivery (Fig. 4a). For the purpose of direct comparison to the iboga alkaloids, we chose noribogaine as the standard on the basis of these points: 1) it is the dominant and long circulating molecular species after ibogaine's administration in both humans and rats, ${ }^{17,23}$ 2) noribogaine shows nearly identical effects to ibogaine in rodent OUD and SUD models, ${ }^{14}$ and 3) noribogaine is structurally a close analog of oxa-noribogaine, differing by a single structural change. The specific experimental design (Fig. 4, Methods section) was selected to replicate the previous results ${ }^{14}$ and validate noribogaine as the comparison drug in our experiments. The selected dose of noribogaine $(40 \mathrm{mg} / \mathrm{kg}$, i.p.) has previously been established as a highly efficacious dose in this model that fully suppresses morphine SA acutely, ${ }^{14}$ and corresponds approximately to the lower end of the "psychedelic reset dose" or "flood dose" of ibogaine used in ibogaine clinics.

We found that noribogaine suppressed responding maintained by morphine in the session following administration (day 1 ) and led to a partial but statistically significant suppression of morphine intake on days 2 and 3, returning to pre-treatment level of morphine intake on days 4 and 5 (Fig. 4b). Food reward responding was also suppressed on day 1 (by $>80 \%$ ) but returned to baseline responding on Day 2 . These results replicate the previous studies perfectly in terms of the efficacy (extent of morphine intake suppression), selectivity (drug vs food) and duration of the effect. ${ }^{14}$ We next examined oxa-noribogaine under the same conditions ( 1 injection, $40 \mathrm{mg} / \mathrm{kg}$, i.p.), which induced a stronger and longer-lasting suppression of morphine intake (Fig. 4b, $P=0.0048$ ). The morphine SA suppression was statistically significant for 7 days after a single injection of oxanoribogaine and showed a clear suppression for at least 15 days (Fig. 4b). One subject from this cohort showed $>80 \%$ decrease in morphine intake at the end of the second week (Days 12-15, Extended data Fig. 6a). Food-maintained responding was suppressed on day 1, but largely returned on day 2 , and did not differentiate statistically from vehicle from day 3 onward (Fig. $2 \mathrm{~d}$ ). Thus, the suppression effect of a reset dose of oxa-noribogaine is morphine-specific from day 3 onward. We next examined a $10 \mathrm{mg} / \mathrm{kg}$ dose of oxa-noribogaine (fully analgesic dose in mice, see above), which induced a strong acute suppression of morphine intake ( $>85 \%$ reduction), an effect that is morphine selective as there was a small effect on acute food responding (Fig. 2c, d). Morphine selfadministration largely returned to baseline on subsequent days. Thus, a single $10 \mathrm{mg} / \mathrm{kg}$ dose 
enables selective acute suppression of operant behavior driven by morphine-related reward without affecting behavior motivated by natural rewards.

These remarkable long-term effects induced by a single administration of oxa-noribogaine prompted examination of the effect of repeated dosing, the possibility of dose tapering, and longterm post-treatment effects. The experimental design was in part guided by the clinical experience with ibogaine. According to anecdotal reports, for most opioid dependent subjects attainment of lasting abstinence requires repeated ibogaine reset sessions and or frequent administration of maintenance doses of ibogaine. ${ }^{33}$ We therefore scheduled 2 reset doses $(2 \times 40 \mathrm{mg} / \mathrm{kg}$ ) separated by 4 days (guided by the effect of a single reset dose, Fig. 4b), followed by a maintenance dose (10 $\mathrm{mg} / \mathrm{kg}$ ), and a series of intermittent day-on/day-off administrations of $3 \times 10$ and $3 \times 5 \mathrm{mg} / \mathrm{kg}$ doses, to explore the effect of more frequent administration of lower doses on both acute and day-after efficacy while tapering the dose (Fig. $4 \mathrm{e}, \mathrm{f}$ ).

Overall, this treatment regimen ( 9 oxa-noribogaine administrations over 26 days) significantly reduced morphine SA across all sessions $(P=0.0054)$ and led to a progressive decrease of morphine intake despite the dose tapering. Notably, intermittent $10 \mathrm{mg} / \mathrm{kg}$ doses resulted in complete suppression of morphine intake on days with oxa-noribogaine and increasing efficacy on days without treatment (Fig. $4 \mathrm{e}, \mathrm{f}$ ). Tapering to $5 \mathrm{mg} / \mathrm{kg}$ intermittent doses led to maintenance of low, residual amounts of morphine intake, and remarkably sustained suppression was observed for an extended period of time following the last administration of oxa-noribogaine $1<30 \%$ of pretreatment morphine intake over 2.5 weeks). Examining the responses of individual subjects, some showed high and lasting response to a single reset dose of oxa-noribogaine (as seen above), while others required multiple doses to suppress morphine intake with lasting effects (Extended Data Fig. 6). Importantly, the long-lasting effects are morphine selective as no such suppression effects were observed in food responding (Extended Data Fig. 6d). 

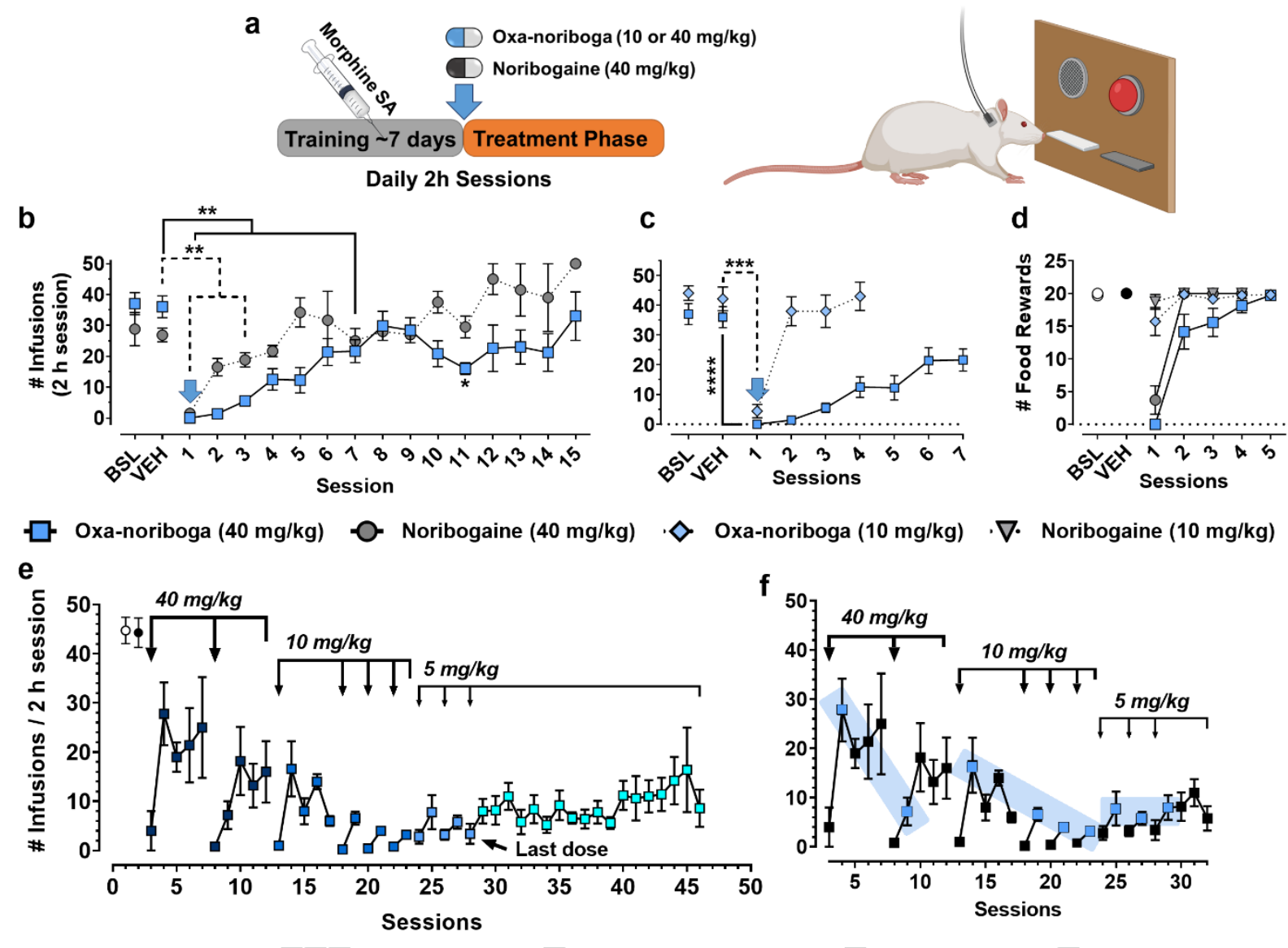

O Baseline $\bullet$ Vehicle $\square \square \square$ Oxa-noriboga $\square$ Post-treatment

Doxa-noriboga $\square$ Day-after Effects

Fig. 4 | Oxa-noribogaine induces acute and long-lasting suppression of morphine selfadministration in rats. a, A schematic depiction of a single dose treatment paradigm of opioid use disorder (OUD) animal model. b, Oxa-noribogaine $(40 \mathrm{mg} / \mathrm{kg})$ is more efficacious than noribogaine $(40 \mathrm{mg} / \mathrm{kg})$ in suppressing morphine self-administration $(P=0.0048)$. One injection of oxa-noribogaine $(40 \mathrm{mg} / \mathrm{kg})$ results in statistically significant suppression of morphine intake for 7 days, with suppression trends observable for at least 2 weeks $(n=5$, see Extended Data Fig. 6 for individual responses). c, The effect on morphine self-administration was dose dependent. Both doses induce strong acute suppression, $40 \mathrm{mg} / \mathrm{kg}$ of oxa-noribogaine is more efficacious than $10 \mathrm{mg} / \mathrm{kg}$ in suppressing morphine self-administration $(P<0.0001)$ with significant differences observed on sessions 2-4. d, Food operant intake (natural reward) is reduced following administration of $40 \mathrm{mg} / \mathrm{kg}$ but not $10 \mathrm{mg} / \mathrm{kg}(P<0.0001)$, with significant reductions observed after $40 \mathrm{mg} / \mathrm{kg}$ on sessions 1 and 2 ( $P<0.0001$ and 0.01876, respectively). The moderate dose $(10 \mathrm{mg} / \mathrm{kg})$ has a marginal effect on food intake indicating drug-selective suppression of responding at this dose. e, The repeated dosing regimen significantly reduced morphine $S A$ across sessions $(P=0.0054)$. Arrows indicate sessions where oxa-noribogaine was administered. Repeated dosing increases oxa-noribogaine's efficacy and leads to persistent morphine intake suppression (experiment terminated 18 days after the last dose). $\mathbf{f}$, Section of panel e where blue highlights indicate the morphine intake on days after oxa-noribogaine administration (after-effects), when oxa-noribogaine is essentially eliminated from the plasma 
and brain. Repeated administration of oxa-noribogaine increases its suppression efficacy on days after its administration, enabling dose tapering. Data are presented as mean $\pm \mathrm{SEM}$, specific statistical tests, information on reproducibility, and $P$ values are reported in Methods and in Supplementary Statistics Table, $* P<0.05, * * P<0.01, * * * P<0.001, * * * * P<0.0001$.

\section{Discussion}

Currently approved medications for treatment of SUDs do not reverse or weaken the persistent negative alterations in neurocircuitry and psychological states that underlie addiction. 3,34 Although considerable progress has been made in the development of animal models of various aspects of addiction phenotypes (e.g. drug intake and cue-induced reinstatement of drug seeking), 4,35,36 the SUD preclinical research have largely focused on drug's acute effects, where typically the desirable effect wanes along with the drug's clearance. In contrast, ibogaine serves as inspiration for a different kind of pharmacotherapeutics capable of inducing profound and lasting interruption of addiction states in drug dependent human and animal subjects. The central hypothesis for this new direction in drug discovery is that these lasting behavioral effects are driven by desirable neuroplasticity and neuro-restorative alterations of relevant circuitry induced by drugs like ibogaine. In support of this hypothesis, it has been reported that ibogaine and noribogaine induce expression of glial cell derived neurotrophic factor (GDNF) in rats, which in turn resets the function of dopaminergic reward circuitry. ${ }^{15}$ We have recently replicated this result and shown that ibogaine also induces gene expression of brain derived neurotrophic factor (BDNF) in the prefrontal cortex. ${ }^{37}$ It thus appears that multiple neurotrophic systems are activated that may drive synaptic and circuit restoration that underlies the observed interruption of addiction phenotypes.

Considering ibogaine's unique clinical effects, as well as its structural and pharmacological complexities, the iboga system provides a rich discovery platform. ${ }^{21,24}$ We here described the oxa-iboga compounds as a new class of iboga alkaloids created by a single but highly consequential structural permutation of the iboga skeleton. Oxa-noribogaine accentuates KOR agonistic activity, enhances therapeutic-like activity in models of OUD, and addresses cardiotoxicity, in comparison to noribogaine. A single reset dose of oxa-noribogaine leads to suppression of morphine SA for at least 1 week, while repeated dosing increases its efficacy, enables dose tapering, and leads to a persistent suppression of morphine intake. The lasting effects on morphine self-administration are not seen in food responding.

As with all preclinical SUD studies, however, there is the question of predictive validity of the animal models for candidate therapeutics where SA paradigms have a mixed track record. ${ }^{4,38}$ In the present study, the starting point is a drug with large clinical effects (although not yet confirmed in controlled studies) and reverse translation to provide a benchmark for preclinical evaluation of new compounds in terms of both efficacy and safety. In direct comparison to noribogaine, oxanoribogaine is superior in terms of both the efficacy (extent of intake suppression) and duration of the after-effects. For another comparison, 18-methoxycoronaridine (18MC) is a synthetic iboga analog that has progressed through preclinical and Phase I clinical safety studies, but its clinical efficacy has not yet been reported. In preclinical assays in rats $18 \mathrm{MC}$ showed comparable efficacy and duration of effect on morphine intake to ibogaine and noribogaine, ${ }^{39}$ and thus an oxa-iboga analog likely offers a superior iboga candidate for SUD treatment. Ibogaine has also served, in part, as inspiration for the creation of 1,2,3,4,5,6-hexahydroazepino[4,5-b]indoles, for 
example compound U-22394A ("U" for Upjohn Company, also known as PNU-22394) that has been in clinical tests but not for SUD indications. ${ }^{40}$ An analog of PNU-compounds has recently been examined in a heroin SA test in rats and showed no lasting effect on heroin SA beyond the acute and non-selective suppression of heroin and sucrose intake. ${ }^{41}$ However, the PNUcompounds are pharmacologically distinct from iboga, as they are direct ligands of multiple $5 \mathrm{HT}$ receptors and lack activity at KOR and other known iboga targets, while iboga alkaloids have no direct interactions with $5 \mathrm{HT}$ receptors within a relevant concentration range. The PNUcompounds are structurally and pharmacologically related to lorcaserin $(5 \mathrm{HT} 2 \mathrm{C}>5 \mathrm{HT} 2 \mathrm{AR}$ preferring agonist), which prior to its market withdrawal generated excitement in SUD research (e.g. showing suppression of heroin SA in rats $^{42}$ and cocaine SA in monkeys ${ }^{43}$ ). Lorcaserin maintained effective suppression of cocaine SA for an extended period of time by daily dosing prior to SA sessions (14 days), however the suppression effect completely dissipated as soon as the treatment ended. ${ }^{43}$ This example highlights the difference between drugs that are effective acutely, and those - like oxa-iboga and iboga - that may produce lasting or even persistent alterations of addiction-like phenotypes.

The oxa-iboga compounds act as potent KOR agonists in vitro and in vivo but exhibit atypical behavioral features compared to standard kappa psychedelics. Generally, KOR agonists are acutely pro-depressive and aversive; in drug SA studies, the effects vary depending on the experimental design. ${ }^{44}$ For example, mixing in KOR agonist nalfurafine to self-administered oxycodone decreased the opioid intake in rats, ${ }^{45}$ whereas pretreatment with nalfurafine or U50,488 resulted in an increased cocaine intake in mice. ${ }^{46}$ However, the long term effects of kappa psychedelics in drug SA studies have not been systematically examined. Oxa-noribogaine, although a potent KOR agonist, does not show the acute pro-depressive or aversive effects, and induces desirable longterm effects in OUD models. It is not clear what mechanistically imparts these atypical features, whether differential KOR signaling ${ }^{47-50}$ and or polypharmacology, ${ }^{51,52}$ but, as a working hypothesis we propose an interplay between the KOR and the inherited iboga pharmacological activity. This constellation of primary molecular targets likely triggers neurotrophic and neuro-repair signaling pathways in several circuits (e.g. prefrontal control of limbic systems, reward circuitry, and spinal pain circuits). The oxa-iboga alkaloids are a new class of compounds that maintains and enhances the ability of iboga compounds to effect lasting alteration of addiction-like states while addressing iboga's cardiac liability. As such these compounds represent exciting candidates for a new kind of anti-SUD pharmacotherapeutics.

\section{Acknowledgements}

This work was supported by Columbia University (D. Sames), The High Point University (S. Hemby), the National Institute on Drug Addiction (NIDA) of the National Institute of Health (NIH), grants R01DA050613 (D. Sames and S. Hemby), R33DA045884 (S. Majumdar), R33DA038858 (V. Katritch), and the National Institute of Mental Health (NIMH), grant R21MH116462 (J. Pintar), and the Hope for Depression Research Foundation (J. A. Javitch). The authors would like to thank William Nguyen, Ky Truong, Lana Rasoul, Alexa Stafford, Guy Page and Dr Richard Kondo for technical assistance and helpful discussions (AnaBios Corporation). V.H. acknowledges the Experientia Foundation Postdoctoral Fellowship. A.H. was supported by the Summer Research fellowship (SuRF) at HPU. We thank Dr. Ignacio Carrera (Universidad de la República, Uruguay) for helpful discussions on iboga pharmacology, and The Psychoactive Drug Screening Program 
(PDSP) at UNC at Chapel Hill for performing receptor panel screening. Certain graphics were created with BioRender.com.

\section{Author contributions}

D.S. conceptualized and supervised the work. V.H. contributed to the design, performed scaleup synthesis, supervised pharmacological characterization including data interpretation and summarized the collected data for publication. A.C.K. contributed to the design, synthesis, and pharmacological characterization of compounds, carried out early synthetic work including reaction development, optimization, and compound characterization and supervised initial pharmacological characterization and data interpretation. B.B. contributed to the scale-up synthesis, contributed to the design and performed mice experiments conducted at Columbia University (tail-flick, open field and forced swim tests) and interpreted the corresponding results. S.M. and L.S. carried out self-administration and conditioned place preference experiments. A.H. trained rats for self-administration studies and conducted the food maintained responding experiments. M.G.W and M.N. performed the BRET functional assays. A.H. performed the opioid binding assays. M.A. performed the tail-flick mice assay comparing WT and KO mice and J.E.P. supervised the tail-flick mice assays with KO mice. C.H. carried out the serotonin transporter inhibition assay. N.A.-G. provided expert consultation for cardiotoxicity studies. S.A.Z. carried out the docking studies and V.K. supervised the docking studies. M. Y. oversaw the in vivo experiments at Columbia University and provided expert guidance. J.A.J. supervised the BRET functional assays and interpretation of the corresponding results. S.M. supervised the binding assays, functional assays and early in vivo mice tests. S.E.H. designed, guided and supervised the CPP tests in mice, self-administration studies in rats, and interpretation of the corresponding results. D.S. wrote the manuscript with significant help from V.H. and S.E.H. All authors contributed to editing of the manuscript.

\section{Conflict of Interests}

V.H., A.C.K, B.B., M.G.W, J.A.J., S.E.H and D.S. are named inventors on a patent(s) related to oxaiboga compounds. A.C.K and D.S. are co-founders of Gilgamesh Pharmaceuticals. All other authors declare no competing interests.

\section{Materials \& Correspondence}

Correspondence and requests for materials should be addressed to D.S (ds584@columbia.edu).

\section{Reporting summary}

Further information on research design is available in the Nature Research Reporting Summary linked to this paper.

\section{Data availability}

Raw data are available from authors upon reasonable request.

\section{Code availability}

Custom-written data analysis codes are available from authors upon reasonable request. 


\section{References}

1. Jalal, H. et al. Changing dynamics of the drug overdose epidemic in the United States from 1979 through 2016. Science 361, (2018).

2. Case, A. \& Deaton, A. Deaths of despair and the future of capitalism. (Princeton University Press, 2020).

3. Hyman, S. E., Malenka, R. C. \& Nestler, E. J. Neural Mechanisms of Addiction: The Role of Reward-Related Learning and Memory. Annu. Rev. Neurosci. 29, 565-598 (2006).

4. Heilig, M., Epstein, D. H., Nader, M. A. \& Shaham, Y. Time to connect: bringing social context into addiction neuroscience. Nat. Rev. Neurosci. 17, 592-599 (2016).

5. Alper, K. R. Chapter 1 Ibogaine: A review. in The Alkaloids: Chemistry and Biology vol. 56 138 (Academic Press, 2001).

6. Koenig, X. \& Hilber, K. The Anti-Addiction Drug Ibogaine and the Heart: A Delicate Relation. Molecules 20, 2208-2228 (2015).

7. Nestor, J. Get Clean or Die Trying. Sci. Am. 315, 62-69 (2016).

8. Oaklander, M. Inside Ibogaine, One of the Most Promising and Perilous Psychedelics for Addiction. Time Magazine (2021).

9. Brown, T. K., Noller, G. E. \& Denenberg, J. O. Ibogaine and Subjective Experience:

Transformative States and Psychopharmacotherapy in the Treatment of Opioid Use Disorder.

J. Psychoactive Drugs 51, 155-165 (2019).

10. R. Alper, Howard S. Lotsof, Geerte, K. Treatment of Acute Opioid Withdrawal with Ibogaine. Am. J. Addict. 8, 234-242 (1999).

11. Mash, D. C., Duque, L., Page, B. \& Allen-Ferdinand, K. Ibogaine Detoxification Transitions Opioid and Cocaine Abusers Between Dependence and Abstinence: Clinical Observations and Treatment Outcomes. Front. Pharmacol. 9, 529 (2018).

12. Noller, G. E., Frampton, C. M. \& Yazar-Klosinski, B. Ibogaine treatment outcomes for opioid dependence from a twelve-month follow-up observational study. Am. J. Drug Alcohol Abuse 44, 37-46 (2018).

13. Davis, A. K., Averill, L. A., Sepeda, N. D., Barsuglia, J. P. \& Amoroso, T. Psychedelic Treatment for Trauma-Related Psychological and Cognitive Impairment Among US Special Operations Forces Veterans. Chronic Stress 4, 247054702093956 (2020).

14. Glick, S. D., Pearl, S. M., Cai, J. \& Maisonneuve, I. M. Ibogaine-like effects of noribogaine in rats. Brain Res. 713, 294-297 (1996).

15. Carnicella, S., He, D.-Y., Yowell, Q. V., Glick, S. D. \& Ron, D. Noribogaine, but not 18-MC, exhibits similar actions as ibogaine on GDNF expression and ethanol self-administration: Ibogaine derivatives and GDNF and alcohol. Addict. Biol. 15, 424-433 (2010).

16. Belgers, M. et al. Ibogaine and addiction in the animal model, a systematic review and meta-analysis. Transl. Psychiatry 6, e826-e826 (2016).

17. Rodríguez, P. et al. A Single Administration of the Atypical Psychedelic Ibogaine or Its Metabolite Noribogaine Induces an Antidepressant-Like Effect in Rats. ACS Chem. Neurosci. 11, 1661-1672 (2020).

18. Popik, P., Layer, R. T. \& Skolnick, P. 100 years of ibogaine: neurochemical and pharmacological actions of a putative anti-addictive drug. Pharmacol. Rev. 47, 235-253 (1995). 
19. Wasko, M. J., Witt-Enderby, P. A. \& Surratt, C. K. DARK Classics in Chemical Neuroscience: Ibogaine. ACS Chem. Neurosci. 9, 2475-2483 (2018).

20. Kruegel, A. C., Rakshit, S., Li, X. \& Sames, D. Constructing Iboga Alkaloids via C-H Bond Functionalization: Examination of the Direct and Catalytic Union of Heteroarenes and Isoquinuclidine Alkenes. J. Org. Chem. 80, 2062-2071 (2015).

21. Gassaway, M. M. et al. Deconstructing the Iboga Alkaloid Skeleton: Potentiation of FGF2-induced Glial Cell Line-Derived Neurotrophic Factor Release by a Novel Compound. ACS Chem. Biol. 11, 77-87 (2016).

22. Maillet, E. L. et al. Noribogaine is a G-protein biased k-opioid receptor agonist. Neuropharmacology 99, 675-688 (2015).

23. Baumann, M. H., Pablo, J., Ali, S. F., Rothman, R. B. \& Mash, D. C. Chapter 5 Comparative neuropharmacology of ibogaine and its O-desmethyl metabolite, noribogaine. in The Alkaloids: Chemistry and Biology vol. 56 79-113 (Elsevier, 2001).

24. Bhat, S. et al. Tropane-Based Ibogaine Analog Rescues Folding-Deficient Serotonin and Dopamine Transporters. ACS Pharmacol. Transl. Sci. 4, 503-516 (2021).

25. Pfeiffer, A., Brantl, V., Herz, A. \& Emrich, H. Psychotomimesis mediated by kappa opiate receptors. Science 233, 774-776 (1986).

26. Bruchas, M. R. et al. Stress-Induced p38 Mitogen-Activated Protein Kinase Activation Mediates -Opioid-Dependent Dysphoria. J. Neurosci. 27, 11614-11623 (2007).

27. Mague, S. D. et al. Antidepressant-Like Effects of k-Opioid Receptor Antagonists in the Forced Swim Test in Rats. J. Pharmacol. Exp. Ther. 305, 323-330 (2003).

28. Glue, P. et al. Ascending Single-Dose, Double-Blind, Placebo-Controlled Safety Study of Noribogaine in Opioid-Dependent Patients: Clinical Pharmacology in Drug Development. Clin. Pharmacol. Drug Dev. 5, 460-468 (2016).

29. Nguyen, N. et al. Adult Human Primary Cardiomyocyte-Based Model for the Simultaneous Prediction of Drug-Induced Inotropic and Pro-arrhythmia Risk. Front. Physiol. 8, 1073 (2017).

30. Koenig, X. et al. Anti-addiction drug ibogaine inhibits voltage-gated ionic currents: A study to assess the drug's cardiac ion channel profile. Toxicol. Appl. Pharmacol. 273, 259-268 (2013).

31. Abi-Gerges, N. et al. Multiparametric Mechanistic Profiling of Inotropic Drugs in Adult Human Primary Cardiomyocytes. Sci. Rep. 10, 7692 (2020).

32. Drug reinforcement in animals. in Addiction Medicine: Science and Practice (ed. Johnson, B. A.) $117-128$ (Springer, 2011).

33. Kroupa, P. K. \& Wells, H. Ibogaine in the 21st Century: Boosters, Tune-ups and Maintenance. MAPS 15, 21-24 (2005).

34. Evans, C. J. \& Cahill, C. M. Neurobiology of opioid dependence in creating addiction vulnerability. F1000Research 5, 1748 (2016).

35. Ahmed, S. H. \& Koob, G. F. Transition from Moderate to Excessive Drug Intake: Change in Hedonic Set Point. Science 282, 298-300 (1998).

36. Kuhn, B. N., Kalivas, P. W. \& Bobadilla, A.-C. Understanding Addiction Using Animal Models. Front. Behav. Neurosci. 13, 262 (2019). 
37. Marton, S. et al. Ibogaine Administration Modifies GDNF and BDNF Expression in Brain Regions Involved in Mesocorticolimbic and Nigral Dopaminergic Circuits. Front. Pharmacol. 10, 193 (2019).

38. Shaham, Y. \& de Wit, H. Lost in Translation: CRF1 Receptor Antagonists and Addiction Treatment. Neuropsychopharmacology 41, 2795-2797 (2016).

39. Glick, S. D., Maisonneuve, I. M. \& Szumlinski, K. K. Chapter 2 Mechanisms of action of ibogaine: Relevance to putative therapeutic effects and development of a safer iboga alkaloid congener. in The Alkaloids: Chemistry and Biology vol. 56 39-53 (Elsevier, 2001).

40. Hester, J. B., Tang, A. H., Keasling, H. H. \& Veldkamp, W. Azepinoindoles. I.

Hexahydroazepino[4,5-b]indoles. J. Med. Chem. 11, 101-106 (1968).

41. Cameron, L. P. et al. A non-hallucinogenic psychedelic analogue with therapeutic potential. Nature 589, 474-479 (2021).

42. Neelakantan, H. et al. Lorcaserin Suppresses Oxycodone Self-Administration and Relapse Vulnerability in Rats. ACS Chem. Neurosci. 8, 1065-1073 (2017).

43. Collins, G. T., Gerak, L. R. \& France, C. P. The behavioral pharmacology and therapeutic potential of lorcaserin for substance use disorders. Neuropharmacology 142, 63-71 (2018).

44. Shippenberg, T. S., Zapata, A. \& Chefer, V. I. Dynorphin and the pathophysiology of drug addiction. Pharmacol. Ther. 116, 306-321 (2007).

45. Townsend, E. A. et al. Effects of nalfurafine on the reinforcing, thermal antinociceptive, and respiratory-depressant effects of oxycodone: modeling an abuse-deterrent opioid analgesic in rats. Psychopharmacology (Berl.) 234, 2597-2605 (2017).

46. Dunn, A. et al. Modulation of cocaine-related behaviors by low doses of the potent KOR agonist nalfurafine in male C57BL6 mice. Psychopharmacology (Berl.) 237, 2405-2418 (2020).

47. Liu, J. J. et al. In vivo brain GPCR signaling elucidated by phosphoproteomics. Science 360, eaao4927 (2018).

48. Zhou, L. et al. Development of Functionally Selective, Small Molecule Agonists at Kappa Opioid Receptors. J. Biol. Chem. 288, 36703-36716 (2013).

49. White, K. L. et al. The G Protein-Biased $\kappa$-Opioid Receptor Agonist RB-64 Is Analgesic with a Unique Spectrum of Activities In Vivo. J. Pharmacol. Exp. Ther. 352, 98-109 (2015).

50. Spetea, M. et al. Selective $\mathrm{K}$ receptor partial agonist HS666 produces potent antinociception without inducing aversion after i.c.v. administration in mice: HS666 produces analgesia without causing aversion. Br. J. Pharmacol. 174, 2444-2456 (2017).

51. Váradi, A. et al. Synthesis and Characterization of a Dual Kappa-Delta Opioid Receptor Agonist Analgesic Blocking Cocaine Reward Behavior. ACS Chem. Neurosci. 6, 1813-1824 (2015).

52. Paton, K. F., Atigari, D. V., Kaska, S., Prisinzano, T. \& Kivell, B. M. Strategies for Developing $\kappa$ Opioid Receptor Agonists for the Treatment of Pain with Fewer Side Effects. J. Pharmacol. Exp. Ther. 375, 332-348 (2020). 


\section{Extended Data Figures}
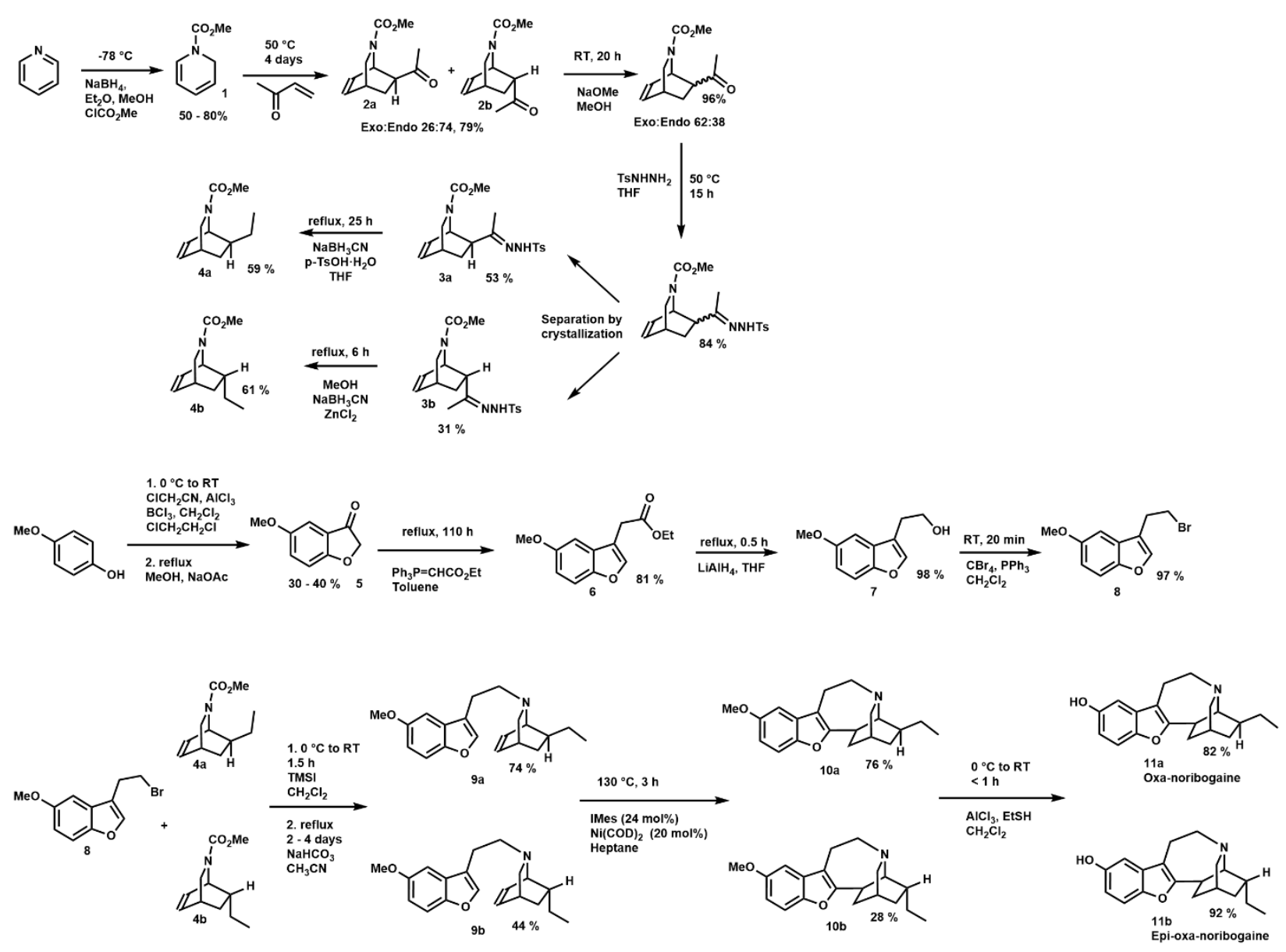

Extended Data Fig. 1 | Synthesis of oxa-iboga analogs. The isoquinuclidine ring was assembled via a Diels-Alder reaction using the dihydropyridine 1 . The key next step involved the nickelcatalyzed coupling between the benzofuran and isoquinuclidine moieties to produce the oxaiboga core structure. 

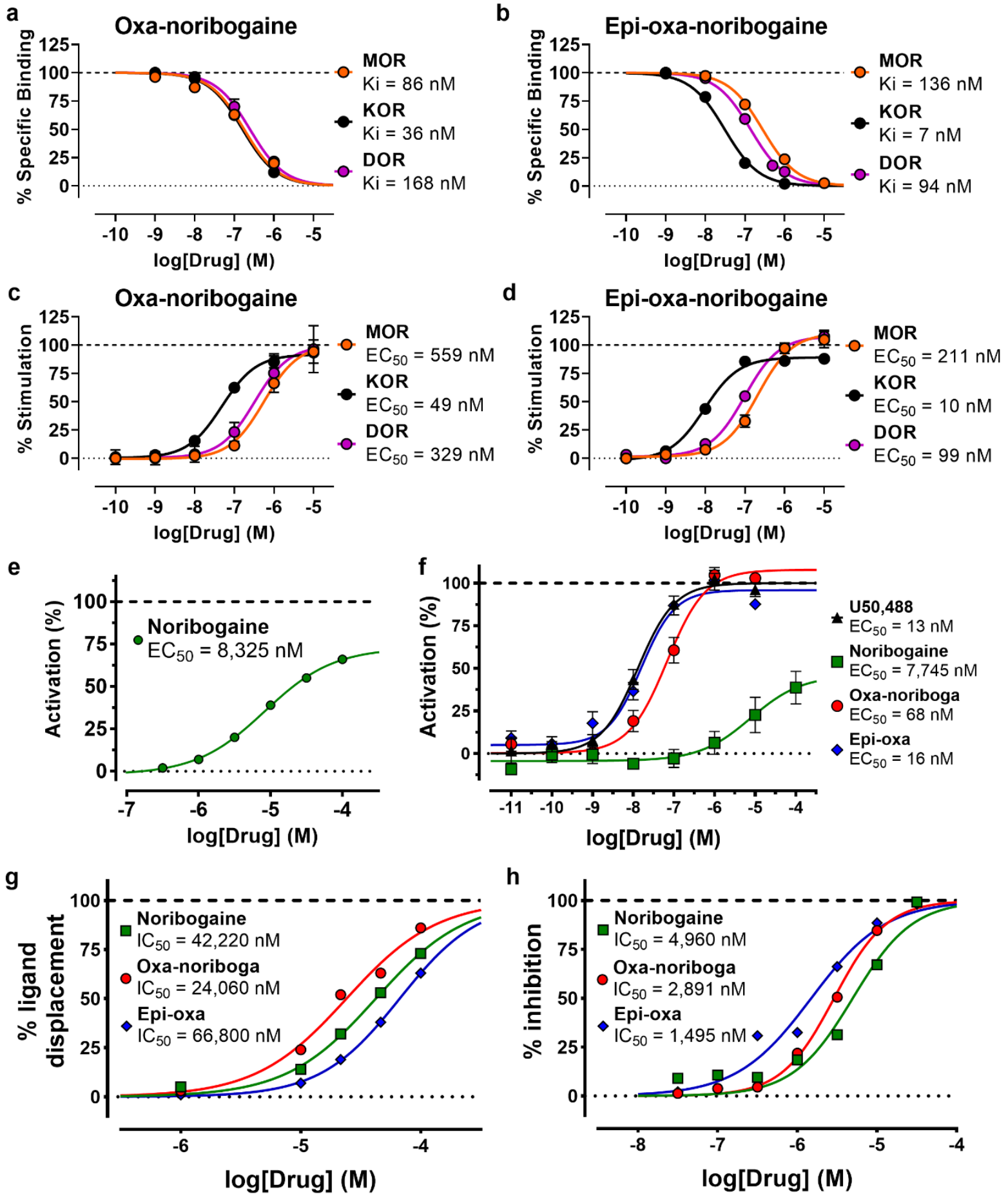

Extended Data Fig. 2 | In vitro pharmacological characterization of noribogaine and oxa-iboga analogs. a,b, Binding affinity measured by radioligand ([125I]-IBNtxA) displacement experiments at mouse opioid receptors (mMOR, mKOR and mDOR) for oxa-noribogaine and epi-oxanoribogaine. $\mathbf{c}, \mathbf{d}$ Agonist activity at mouse opioid receptors determined by $\left[{ }^{35} \mathrm{~S}\right] \mathrm{GTP} \gamma \mathrm{S}$ assay for oxa-noribogaine and epi-oxa-noribogaine. e, Agonist activity of noribogaine at human KOR determined by $\left.{ }^{35} S\right] G T P \gamma S$ assay. f, Human KOR agonist activity (G protein BRET assay) for 
noribogaine and oxa-noribogaine analogs. g, Binding affinity (radioligand displacement assay) of iboga alkaloids at rat NMDA receptor. $\mathbf{h}$, Inhibition of human nicotinic acetylcholine receptor (nAChR $\alpha 3 \beta 4$ ) by iboga alkaloids as determined by electrophysiological assays. Data are presented as mean \pm SEM. 

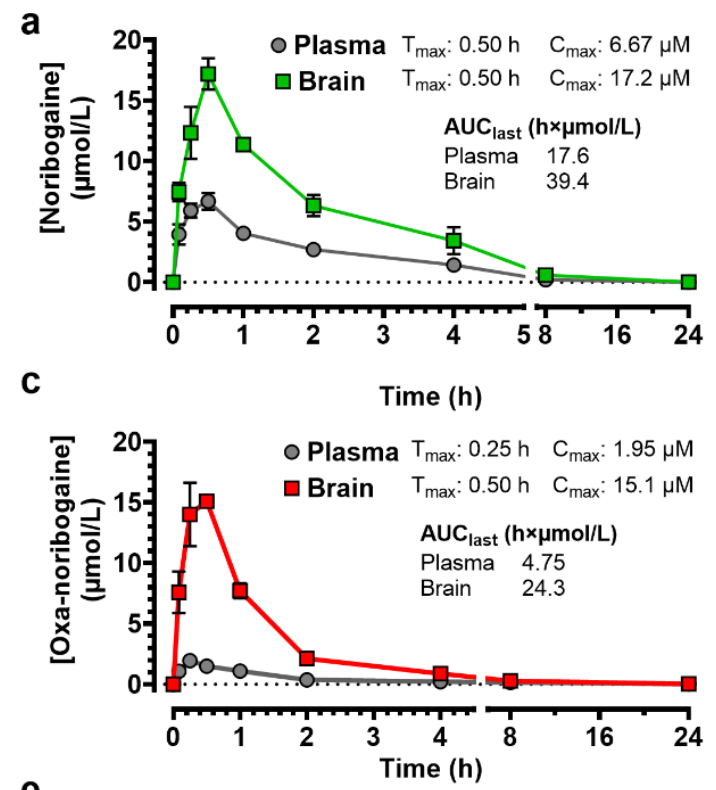

e
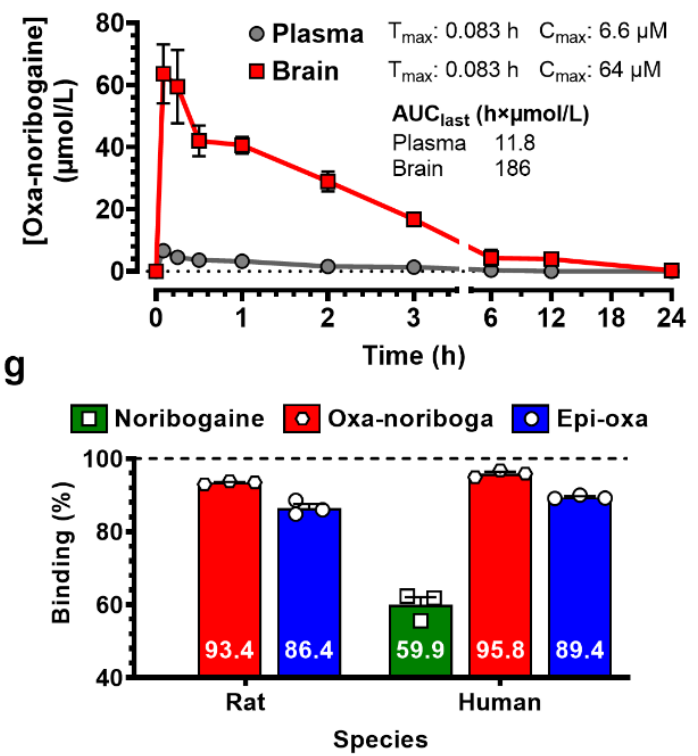

b

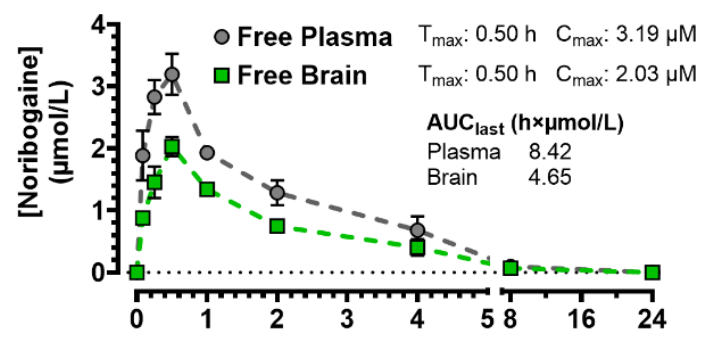

d

Time (h)
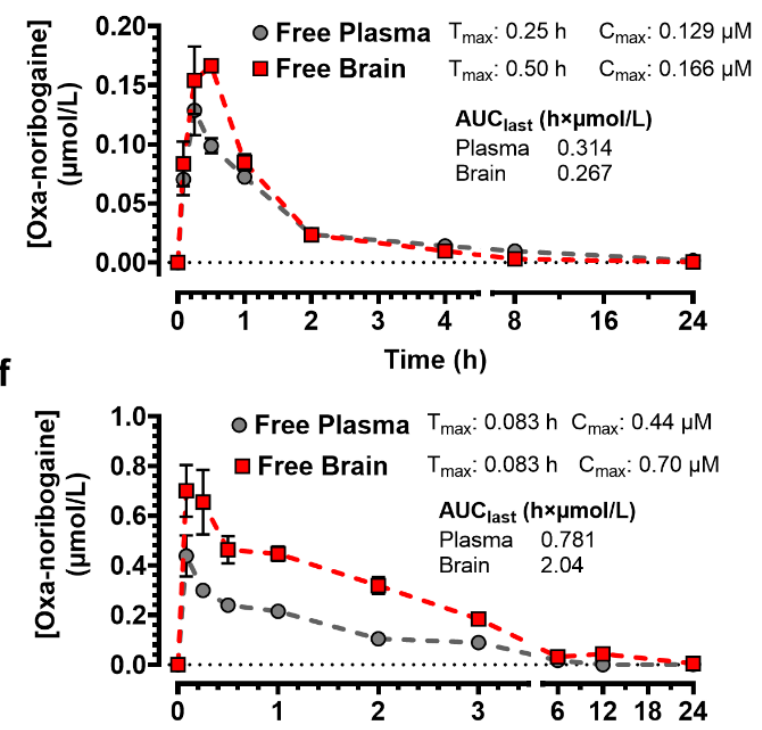

h

Time (h)

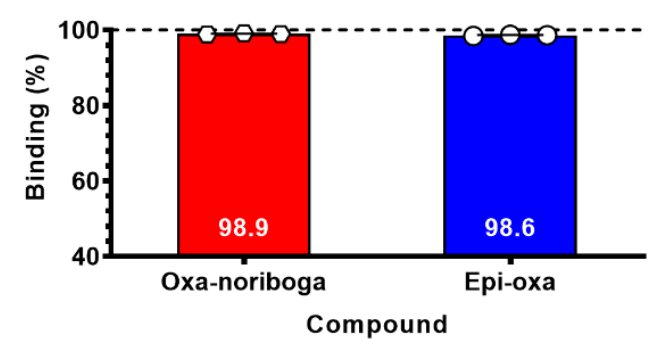

Extended Data Fig. 3 | Pharmacokinetic (PK) distribution (mice, rats), and plasma protein (rats, human) and brain tissue (rat) binding of noribogaine and oxa-iboga analogs. Noribogaine (s.c. $10 \mathrm{mg} / \mathrm{kg}$ ) PK in male C57BL/6 mice, a total and b estimated free concentrations. c, Oxanoribogaine exhibits rapid and high brain penetration in PK (male C57BL/6 mice, s.c. $10 \mathrm{mg} / \mathrm{kg}$, brain/plasma $=5.5$ ). Approximately $85 \%$ of the compound is cleared in the first 2 hours and only traces remain after 8 hours. d, Estimated free plasma and brain drug concentrations. Assuming linearity of PK below $10 \mathrm{mg} / \mathrm{kg}, C_{\max (\text { brain) }}$ at an ED 50 analgesic dose $(3 \mathrm{mg} / \mathrm{kg})$ is expected to be $49 \mathrm{nM}$, which matches very well the in vitro KOR activation potency $\left(\mathrm{EC}_{50}=41 \mathrm{nM}\right.$ in BRET assay, $\mathrm{EC}_{50}=49 \mathrm{nM}$, in $\left[{ }^{35} \mathrm{~S}\right] \mathrm{GTP} \gamma \mathrm{S}$ assay). Oxa-noribogaine (i.p. $40 \mathrm{mg} / \mathrm{kg}$ ) PK in male Wistar rats, e total and $\mathbf{f}$ estimated free concentrations. Rat plasma protein and brain tissue binding data were used to estimate free drug fractions in mice. The $C_{\max }$ and area under the curve (AUC, drug exposure) 
values for estimated free drugs are much smaller for oxa-noribogaine in comparison to noribogaine which is relevant for interpreting the oxa-noribogaine's superior efficacy in addiction models. $\mathbf{g}$, Rat and human plasma protein binding and $\mathbf{h}$ rat brain tissue binding data of noribogaine and oxa-iboga analogs. Data are presented as mean \pm SEM. 

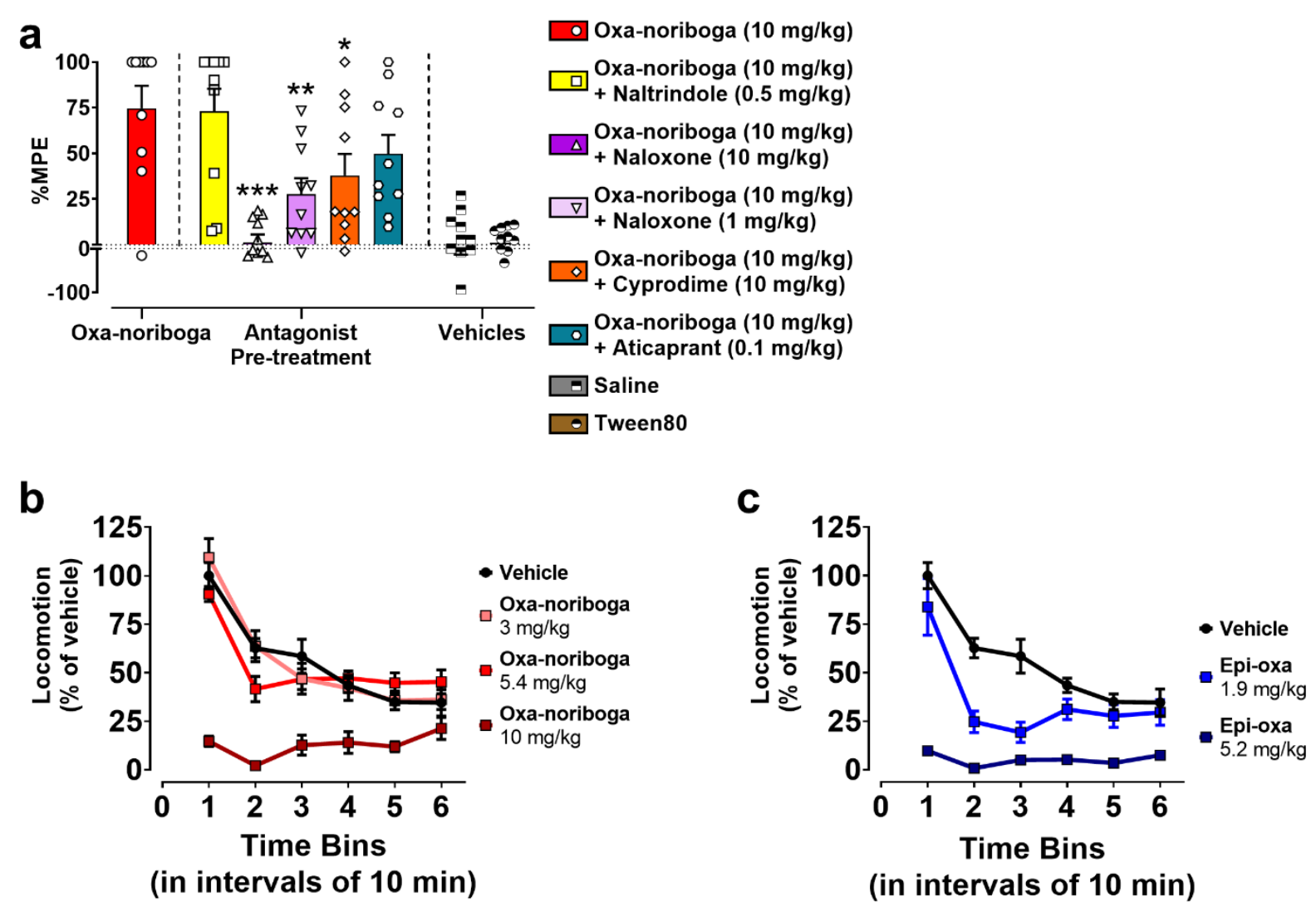

Extended Data Fig. 4 | In vivo characterization of oxa-noribogaine analogs by tail-flick test before and after pre-treatment with opioid antagonists. a, Effect of pre-treatment with antagonists naltrindole (DOR selective), naloxone (non-selective at $10 \mathrm{mg} / \mathrm{kg}$, MOR preferring at $1 \mathrm{mg} / \mathrm{kg}$ ), cyprodime (MOR selective) and aticaprant (KOR selective) on oxa-noribogaine induced nociception. b, Escalating dose effect of oxa-iboga analogs on locomotion in OF test. Oxanoribogaine $\left(3.0 \mathrm{mg} / \mathrm{kg}=\mathrm{ED}_{50}, 5.4 \mathrm{mg} / \mathrm{kg}=\mathrm{ED}_{80}\right.$ and $\left.10 \mathrm{mg} / \mathrm{kg}>\mathrm{ED} 95\right)$ and c epi-oxa-noribogaine $\left(1.9 \mathrm{mg} / \mathrm{kg}=\mathrm{ED}_{50}\right.$ and $\left.5.2 \mathrm{mg} / \mathrm{kg}=\mathrm{ED}_{80}\right)$. Data are presented as mean $\pm \mathrm{SEM}$, specific statistical tests, information on reproducibility, and $P$ values are reported in Methods and in Supplementary Statistics Table, $* P<0.05, * * P<0.01, * * * P<0.001$. 

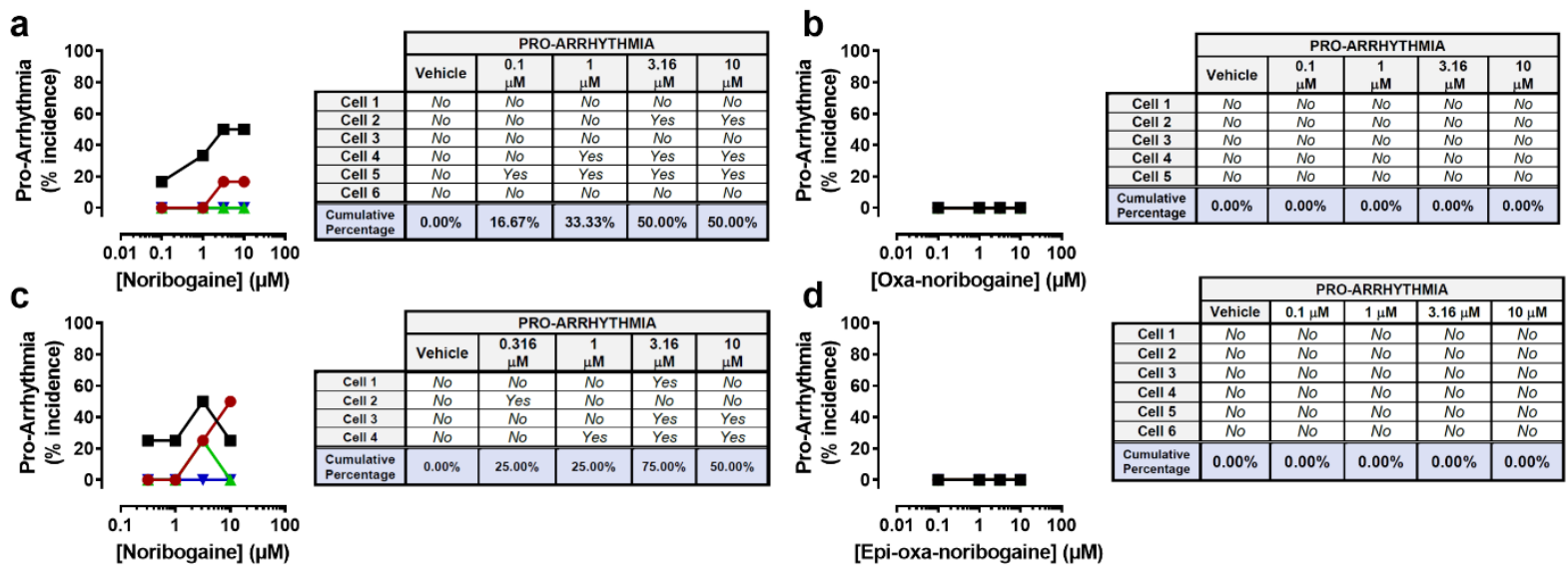

[Epi-oxa-noribogaine] $(\mu \mathrm{M})$

$f$

$\mathbf{f}$
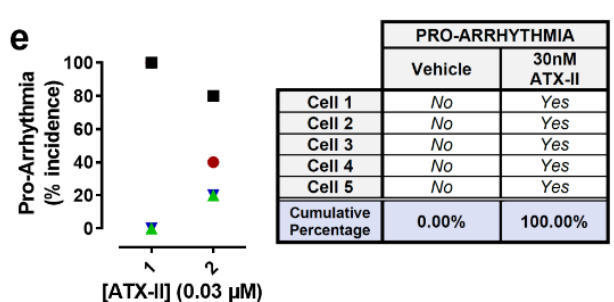

\begin{tabular}{cccccccc}
\hline \# & Age & Sex & Ethnicity & $\begin{array}{c}\text { Body Mass } \\
\text { Index (BMI) }\end{array}$ & $\begin{array}{c}\text { Cause of Death } \\
\text { (COD) }\end{array}$ & $\begin{array}{c}\text { Ejection } \\
\text { Fraction (EF) }\end{array}$ & Study \\
\hline 1 & 37 & M & Hispanic & 29.1 & CVA/ICH/Stroke & N/A & a, b, e1 \\
\hline 2 & 24 & M & Caucasian & 31.1 & Blunt Injury & N/A & c \\
3 & 43 & M & Caucasian & 28.5 & Anoxia & $80 \%$ & d, e2 \\
\hline
\end{tabular}

CVA = Cerebrovascular Accident, $\mathbf{I C H}=$ Intracranial Hemorrhage $\mathbf{N} / \mathbf{A}^{*}=$ Not Available, ${ }^{*}$ Organ procurement organization could not transplant the heart and consequently no echocardiography was performed.

Extended Data Fig. 5 | Pro-arrhythmia risk of noribogaine and oxa-iboga analogs examined in human primary cardiomyocytes. Noribogaine, a, was compared to oxa-noribogaine, b, using cardiomyocytes isolated from the same donor heart. c, Comparable and concentrationdependent pro-arrhythmia risk was detected for noribogaine across 2 donors. d, Epi-oxanoribogaine shows no risk of pro-arrhythmia. e, Anemone toxin, ATX-II, was used as a positive control. f, Donor information. 
a

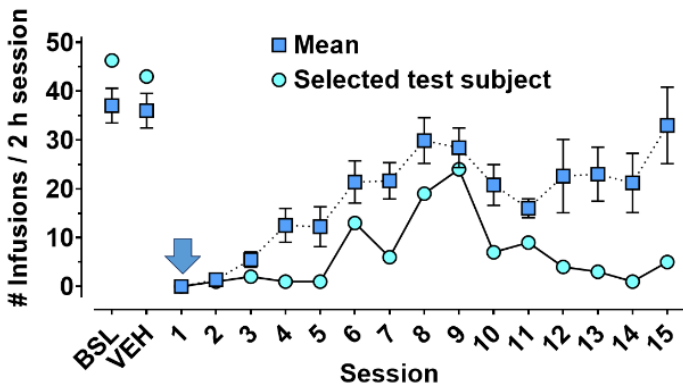

b

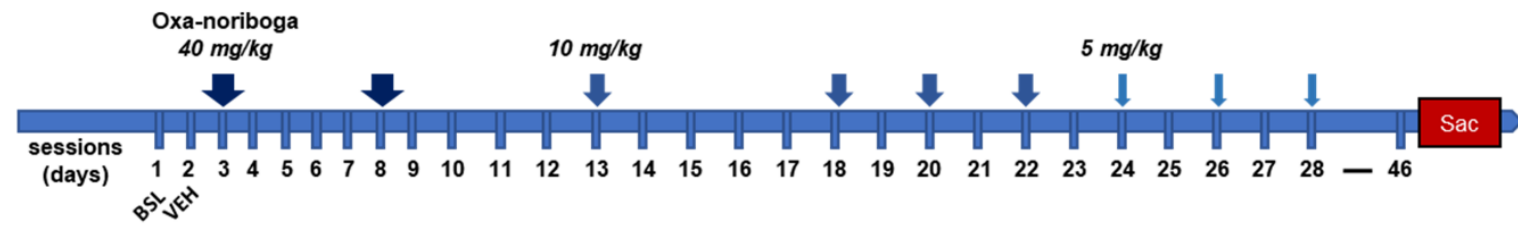

C

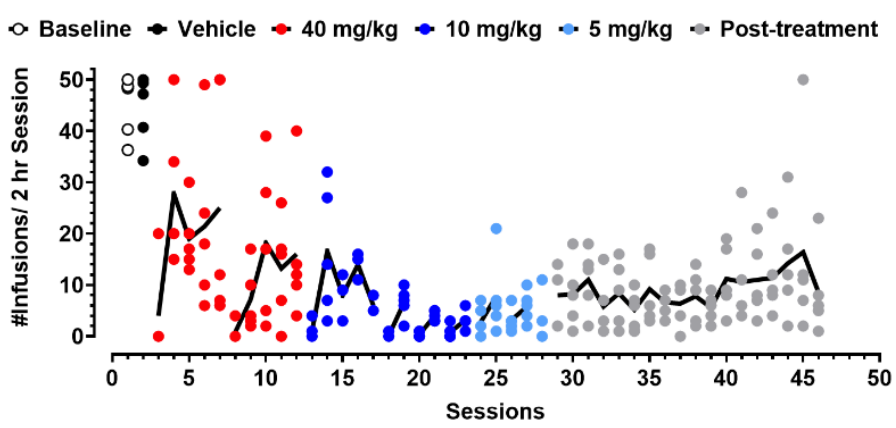

e
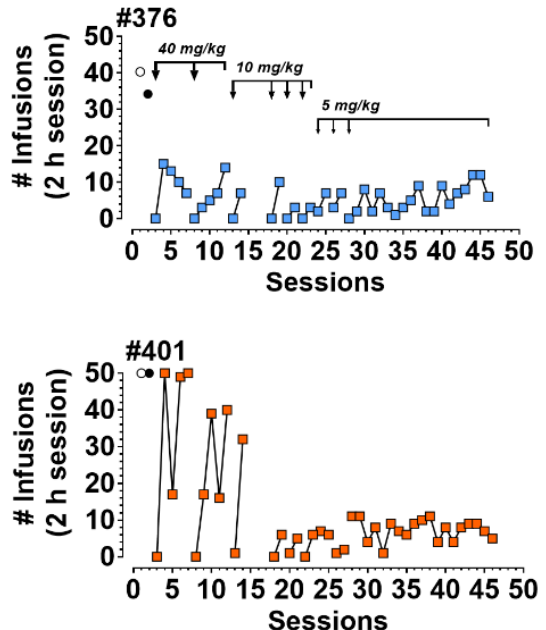

d

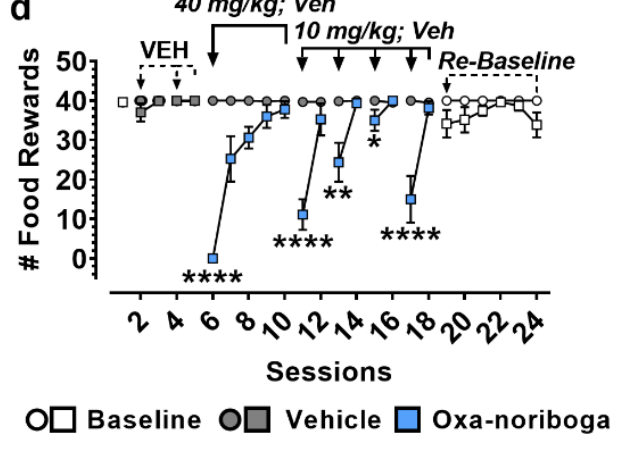

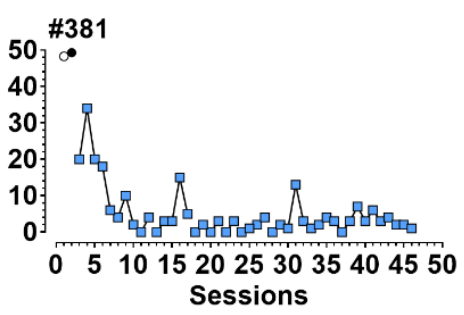
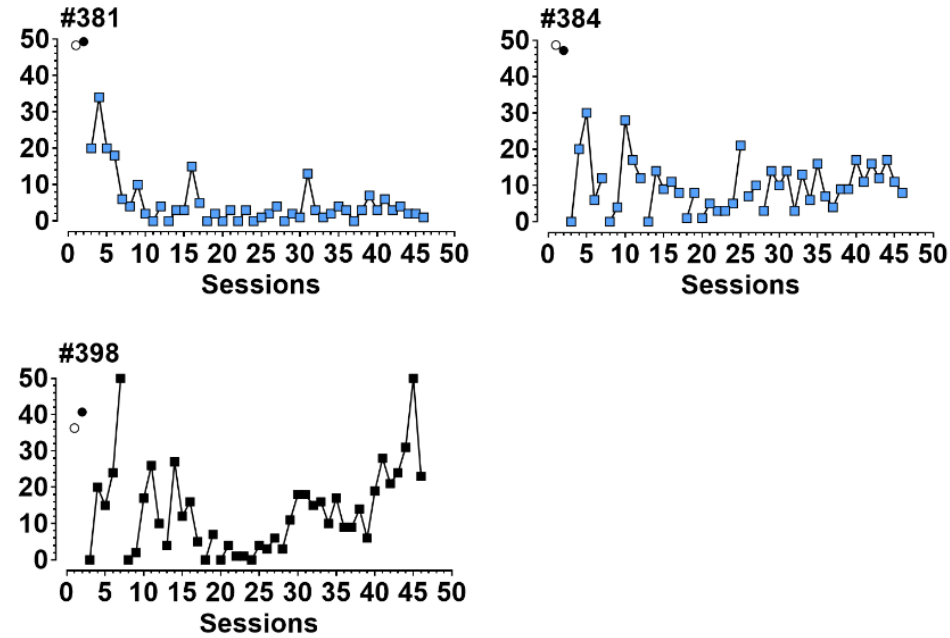

Extended Data Fig. 6 | Morphine self-administration in rats. a, Morphine intake for one test subject that showed a profound and lasting morphine intake suppression ( $>14$ days) after a single dose of oxa-noribogaine before session $1(40 \mathrm{mg} / \mathrm{kg}$, i.p.). The mean response of the entire cohort is shown for comparison. $\mathbf{b}$, Experimental design of the repeated dosing regimen in morphine SA initiated by $40 \mathrm{mg} / \mathrm{kg}$ ("psychedelic reset dose"), followed by 10 and $5 \mathrm{mg} / \mathrm{kg}$ doses ("maintenance doses") of oxa-noribogaine. c, Cumulative effect of the regimen of reset (40 
$\mathrm{mg} / \mathrm{kg}$ ) and maintenance (10 and $5 \mathrm{mg} / \mathrm{kg}$ ) doses of oxa-noribogaine resulted in sustained suppression of morphine intake. Individual data points are visualized with mean values depicted using solid lines. d, Food maintained responding observed after a $40 \mathrm{mg} / \mathrm{kg}$ dose followed by four repeated $10 \mathrm{mg} / \mathrm{kg}$ doses of oxa-noribogaine. While the administration significantly suppresses food responding acutely ( $40 \mathrm{mg} / \mathrm{kg}: \mathrm{P}<0.0001$, responses vary for repeated $10 \mathrm{mg} / \mathrm{kg}$ doses), the response of test subjects was no different than the control group subjects on the days after administration. No significant deviation of responding was observed between the test and the control group subjects over a 7 day period after the treatment was completed. e, Treatment response of individual subjects in the morphine SA study. Subjects \#376, \#381 and \#384 strongly responded to the initial $40 \mathrm{mg} / \mathrm{kg}$ reset doses leading to a lasting suppression of morphine intake. Subject \#401 required multiple doses to subdue morphine intake and induce a long term suppression, while subject \#398 responded to the treatment and showed lasting effects, but started to return toward basal morphine responding in the last 10 days of the experiment. Data are presented as mean \pm SEM, specific statistical tests, information on reproducibility, and $P$ values are reported in Methods and in Supplementary Statistics Table, $* P<0.05, * * P<0.01$, $* * * P<0.001, * * * * P<0.0001$. 